\title{
Human C. difficile toxin-specific memory B cell repertoires encode poorly neutralizing antibodies
}

\author{
Hemangi B. Shah, ${ }^{1}$ Kenneth Smith, ${ }^{2}$ Edgar J. Scott II, ${ }^{1}$ Jason L. Larabee, ${ }^{1}$ Judith A. James, ${ }^{2,3}$ \\ Jimmy D. Ballard, ${ }^{1}$ and Mark L. Lang ${ }^{1}$ \\ 'Department of Microbiology and Immunology, University of Oklahoma Health Sciences Center (OUHSC), ${ }^{2}$ Arthritis and \\ Clinical Immunology, Oklahoma Medical Research Foundation, and ${ }^{3}$ Departments of Medicine and Pathology, OUHSC, \\ University of Oklahoma, Oklahoma City, Oklahoma, USA.
}

\begin{abstract}
Clostridioides difficile is a leading cause of nosocomial infection responsible for significant morbidity and mortality with limited options for therapy. Secreted C. difficile toxin B (TcdB) is a major contributor to disease pathology, and select TcdB-specific Abs may protect against disease recurrence. However, the high frequency of recurrence suggests that the memory $B$ cell response, essential for new Ab production following $C$. difficile reexposure, is insufficient. We therefore isolated TcdB-specific memory B cells from individuals with a history of $C$. difficile infection and performed single-cell deep sequencing of their Ab genes. Herein, we report that TcdB-specific memory B cell-encoded antibodies showed somatic hypermutation but displayed limited isotype class switch. Memory $B$ cell-encoded $m A b$ generated from the gene sequences revealed low to moderate affinity for TcdB and a limited ability to neutralize TcdB. These findings indicate that memory $B$ cells are an important factor in $C$. difficile disease recurrence.
\end{abstract}

Conflict of interest: The authors have declared that no conflict of interest exists.

\section{Submitted: March 13, 2020 \\ Accepted: July 8, 2020}

Published: August 20, 2020

Reference information: /CI Insight. 2020;5(16):e138137.

https://doi.org/10.1172/jci. insight.138137.

Copyright: (c) 2020, Shah et al. This is an open access article published under the terms of the Creative Commons Attribution 4.0 International License.

\section{Introduction}

Clostridioides difficile is responsible for almost half a million infections and 30,000 deaths in the US annually (1), and it is a significant global health issue (2-5). C. difficile colonization of the large intestine results in symptoms ranging from diarrhea to life-threatening pseudomembranous colitis, sepsis, and even death (6-11). The causes of $C$. difficile-associated mortality are not entirely clear, but case reports suggest that systemic sequelae of the disease are contributory (12). Systemic complications of $C$. difficile reported to date include hepatic abscesses (13), ascites (14), pleural effusion and acute respiratory distress $(15,16)$, and sepsis and multiorgan failure (10).

The enteric and systemic pathology associated with $C$. difficile infection (CDI) is attributable to secreted toxins known as $C$. difficile toxin A (TcdA) and $C$. difficile toxin B (TcdB) (17-19). These toxins enter target cells and glucosylate Rho GTPases to facilitate broad cellular damage (20, 21). Blood-borne TcdA and TcdB can be detected in some patients and are toxic to target cells in vitro (22). However, TcdA-negative strains can also be highly virulent $(19,23)$, and although there is a recent report of disease associated with a TcdB-negative strain (24), it is clear that TcdB is a major driver of disease. TcdB has systemic toxicity in several animal species (25-28), supporting the observations of systemic pathology in patients.

There are several distinct ribotypes and strains of pathogenic $C$. difficile that cause disease of varying severity (29). Infection with a hypervirulent $C$. difficile strain such as the NAP1/BI/027 (ribotype 027) is associated with more severe disease than a historical strain such as VPI-10463 (ribotype 003) (30-32) Mutation of TcdB is likely to contribute to differences in disease severity. Although NAP1/BI/027 toxin B (TcdB2) and VPI-10463 toxin B (TcdB1) share 92\% sequence identity and are similarly immunogenic (33), TcdB2 is more cytotoxic than TcdB1 (28).

As many as $30 \%$ of individuals with an initial CDI will suffer from disease recurrence (34). There are several risk factors for recurrence, including antibiotic use, advanced age, immune response, and the $C$. difficile strains to which patients are exposed (35-39). Recurrent CDI is characterized by regrowth of bacteria that have survived antibiotic therapy or by reinfection with $C$. difficile, and each recurrence increases the probability of further episodes (40). Recurrence is associated with progressively worsening pathology and increasing mortality (41). 
C. difficile recurrence indicates that an initial infection failed to adequately immunize the individual and confer protection against subsequent infection. Indeed, patients with higher anti-TcdA and -TcdB serum IgG titers have lower rates of recurrence, and TcdB-specific IgG is the best known correlate of protection against $C$. difficile $(37,42-45)$. For example, in 2 independent studies of patients with CDI, recruiting 99 and 61 patients, respectively, high serum titers of TcdB-binding and/or -neutralizing IgG were associated with a lower rate of disease recurrence $(43,45)$. Bacterial load during infection correlates directly with age and inversely with TcdB-neutralizing IgG titers (46). There is also indirect evidence for protective humoral immunity. CDI risk is increased in HIV-infected individuals with declining CD4 ${ }^{+}$Th cell counts (47) and in immunosuppressed organ transplant recipients (48). The quality of the IgG response is also important for protection - for example, the TcdB-neutralizing FDA-approved IgG mAb bezlotoxumab binds TcdB with high affinity (49). In a clinical trial, of 200 patients (101 on mAb therapy and 99 on placebo), recurrence was cut by approximately $80 \%$ (50). In 2 subsequent double-blind phase III trials of 2655 patients, recurrence was cut by approximately $60 \%(51)$. The binding affinity of mAbs to TcdB has only been examined in the context of therapeutic mAbs thus far and needs to be evaluated for Abs from past CDI patients.

Despite the clear association between TcdB-neutralizing IgG and disease protection, B cell memory following CDI is not well characterized, and its consequences for recurrent infection are poorly defined. Antigen-activated B cells can differentiate into short- or long-lived Ab-secreting plasma cells or into memory B (Bmem) cells (reviewed in refs. 52, 53). Restimulation of Bmem cells with booster vaccines or repeat infections can drive their differentiation into new Ab-secreting plasma cells with the added benefit of speed, increased magnitude, prior isotype switch, and somatic hypermutation (SHM) to generate high-affinity Ab.

Weak toxin-specific Bmem cell responses in individuals with CDI were demonstrated previously by our lab and others $(33,54)$. This warrants a detailed analysis of the Bmem cell-encoded Ab to identify the underlying defects that may prevent an adequate response. We therefore profiled the TcdB-specific Bmem cell repertoire in individuals who had a prior CDI. These individuals self-reported having been diagnosed with CDI, with 1 requiring hospitalization due to CDI. The carboxy-terminal domain (CTD) of TcdB consists of combined repetitive oligopeptides (CROPs) that are known to contain neutralizing epitopes (55, 56). Although infection with strain VPI-10463 is unlikely, the Abs to TcdB1 and TcdB2 are highly cross-reactive (57). We therefore used fluorophore-conjugated CTD (amino acids 1651-2366) of TcdB1 to identify specific Bmem cells in the PBMC of individuals with a history of CDI. Using single-cell barcoding and deep sequencing of bulk-sorted CTD-specific Bmem cells, we generated several hundred complete Ab gene sequences for 3 individuals. Analysis of the $\mathrm{Ab}$ features revealed a low degree of isotype switch, with IgM dominating the repertoires. The IgG-encoding Bmem cells demonstrated a high degree of SHM. The IgM, IgA, and IgG repertoires were also dominated by unique clones, indicating very limited clonal expansion. The IgG1 gene sequences were expressed in vitro, resulting in production of 49 full-length, intact IgG1 mAbs. While $50 \%$ of the mAbs showed demonstrable binding to TcdB1 and TcdB2, only $1 \mathrm{mAb}$ neutralized TcdB2 in vitro. These data show that the Bmem cell repertoire following CDI encodes affinity-matured Abs that are likely to provide limited protection against TcdB-driven pathogenesis. These results may contribute to an explanation for recurrent disease following CDI.

\section{Results}

Detection of CTD-specific Bmem cells in individuals with a history of CDI and preparation for repertoire analysis. Blood samples were collected from study participants described in Supplemental Table 1 (supplemental material available online with this article; https://doi.org/10.1172/jci.insight.138137DS1) before enrichment of total $\mathrm{B}$ cells (Figure 1A). Flow cytometry was performed to identify singlet CD3-CD $19^{+} \mathrm{CD} 20^{+} \mathrm{CD} 27^{+} \mathrm{CD} 38^{-} \mathrm{CTD}^{+}$ Bmem cells and $\mathrm{CD}^{-} \mathrm{CD} 19^{+} \mathrm{CD} 20^{+} \mathrm{CD} 27^{+} \mathrm{CD} 38^{-} \mathrm{CTD}^{-}$Bmem cells (Figure 1B). CTD-binding Bmem cells were typically undetectable or present at very low frequencies in individuals who had no known history of CDI (Figure 1C). Therefore, populations of CTD-specific Bmem cells could readily be detected and distinguished from Bmem cells of other specificities. $\mathrm{CTD}^{+}$and $\mathrm{CTD}^{-} \mathrm{Bmem}$ cells were then sorted and processed as described in Methods to generate a library of barcoded Ig sequences that was, in turn, curated to analyze the CTD-specific Bmem repertoire, as well as the total nonspecific (CTD $)$ repertoire (Figure $1 D)$. The full gating strategy for sorting $\mathrm{CTD}^{+}$and $\mathrm{CTD}^{-}$Bmem cells and the specificity of $\mathrm{CTD}$ binding to $\mathrm{B}$ cell antigen receptors (BCR) is depicted in Supplemental Figures 1 and 2.

In addition to flow cytometry, we used a second method to detect $\mathrm{CTD}^{+} \mathrm{IgG}^{+}$Bmem cells, following polyclonal stimulation in vitro. PBMCs isolated from subjects 1008, 1009, and 1013 and 3 other subjects, 
A

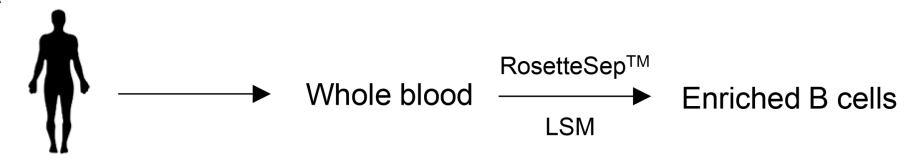

B

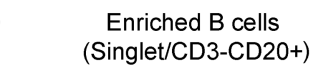

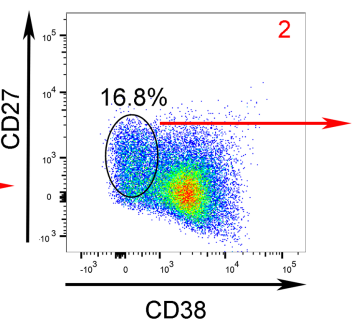

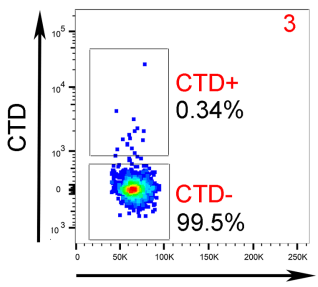

FSC
C

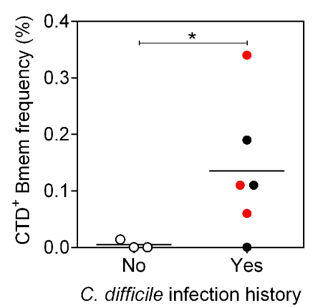

D

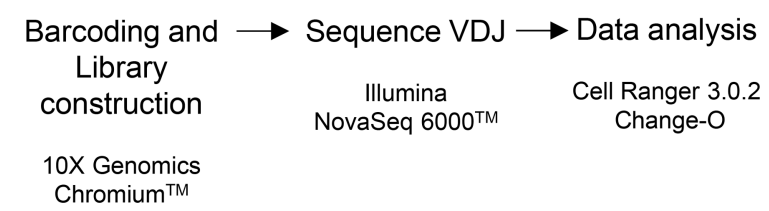

Figure 1. Isolation, sequencing, and repertoire analysis of CTD-specific Bmem cells. (A) Blood samples were obtained from subjects with a history of CDI and used as a source of enriched B cells. (B) Enriched B cells were labeled with a cocktail of fluorochrome-conjugated mAbs and Alexa 488-conjugated CTD as described in Methods. Pseudocolor plots 1 through 3 depict the gating strategy, allowing identification and sorting of CD19+CD2O+C-

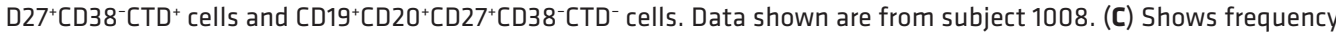
of $\mathrm{CTD}^{+}$Bmem in 3 healthy controls versus 6 previously infected subjects. The subjects included in the single-cell analysis are denoted by red symbols: subjects $1008(0.34 \%), 1009(0.06 \%)$, and $1013(0.11 \%)$. Black dots denote other subjects recruited: subjects $1012(0 \%), 1015$ (0.11\%), and 1018 (0.19\%). The line indicates the mean. A 2-tailed unpaired $t$ test with Welch's correction was applied to determine statistical significance in the differences observed $\left({ }^{*} P<0.05\right)$. (D) Sorted CTD+ and CTD- Bmem cells were processed as depicted and described in Methods, resulting in the generation of individually barcoded and fully sequenced $V(D)$ J regions for each Bmem cell. FASTA files were generated using the Cell Ranger 3.0.2 pipeline, and the Change- 0 toolkit was used to analyze the data.

as well as 4 healthy controls, were cultured with polyclonal stimuli to drive differentiation of Bmem cells into new IgG-secreting plasmablasts, which could then be detected by ELISPOT (Supplemental Figure 2). The subjects and controls had a similar frequency of total Bmem cell-derived IgG-secreting cells. None of the controls had CTD-specific IgG-secreting cells. Consistent with previous studies, only 1 of the 6 subjects (subject 1008) showed a clearly positive result, with detectable CTD-specific IgG-secreting cells $(33,54)$. This shows that $\mathrm{CTD}^{+}$Bmem cells had a poor capacity to differentiate into new plasmablasts following polyclonal stimulation in vitro.

Lower frequency of class switch in $C T D^{+}$Bmem cells than in $C T D^{-}$Bmem cells. Ig/Ab gene sequences from $\mathrm{CTD}^{+}$and $\mathrm{CTD}^{-}$Bmem cells from subjects 1008, 1009, and 1013 were analyzed, and the heavy chains were grouped according to $\mathrm{Ab}$ class and IgG subclass (Figure 2). A lower proportion of the $\mathrm{CTD}^{+} \mathrm{Bmem}^{-}$ cell-encoded Abs were class-switched (to IgA or IgG) as compared with the $\mathrm{CTD}^{-} \mathrm{Bmem}$ cells. For subjects 1008, 1009, and 1013, the percentages of $\mathrm{CTD}^{+}$Bmem cells that were class-switched to IgG were $14.8 \%, 7.3 \%$, and $11.4 \%$, respectively (Figure $2 \mathrm{~A}$ ). For the CTD ${ }^{-}$Bmem cells, $38.2 \%, 30.1 \%$, and $15.8 \%$ of sequences demonstrated class switch, respectively (Figure $2 \mathrm{~B}$ ). The higher ratio of IgM/IgG expression by $\mathrm{CTD}^{+}$Bmem cells became apparent late in the present study. PBMCs were therefore obtained from an additional subject (subject 1018) and cultured with polyclonal stimuli to drive differentiation of Bmem cells and detect CTD-specific IgG as well as IgM-secreting cells by ELISPOT (Supplemental Figure 3). In those analyses, $\mathrm{CTD}^{+}$Bmem cells were dominated by IgM rather than IgG. In contrast, total Bmem cells (representing the $\mathrm{CTD}^{+}$and $\mathrm{CTD}^{-}$populations) had large frequencies of IgM- as well as IgG-secreting cells. 
A CTD $^{+}$Bmem
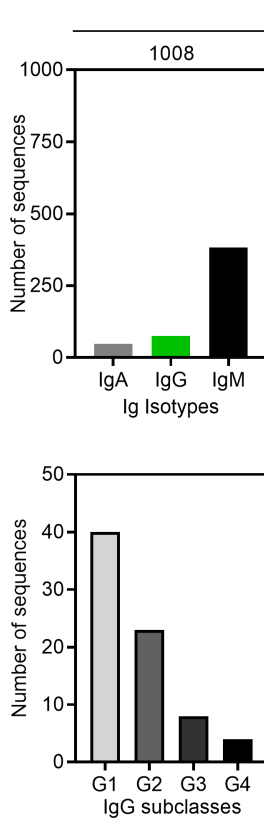

Subject
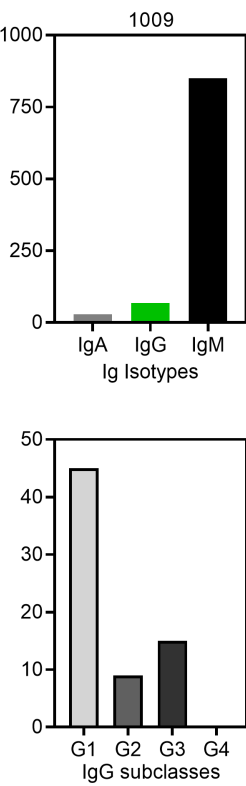
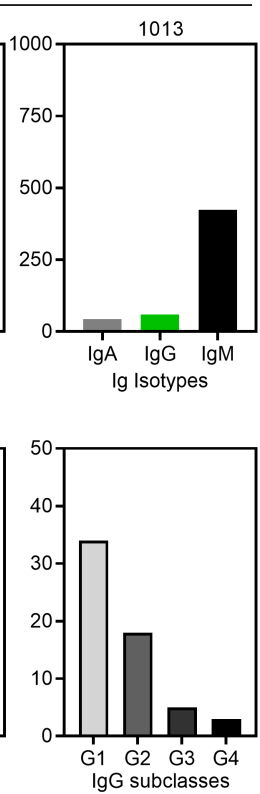

B
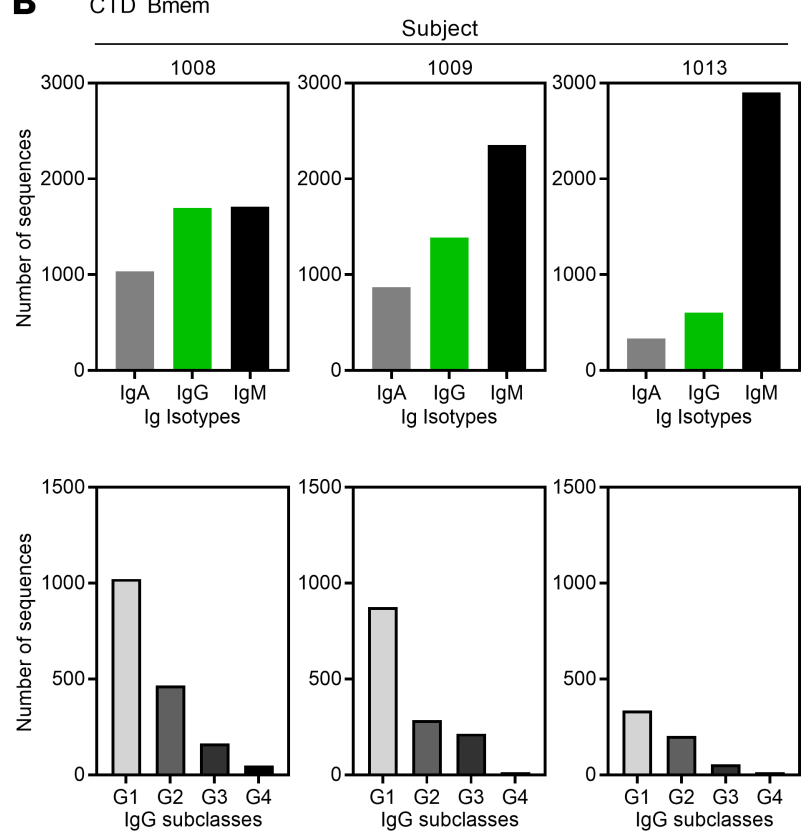

Figure 2. Antibody isotype and subclass distribution in Bmem cells. (A) Sequences from CTD+ Bmem cells were analyzed for isotype (top row) and IgC subclass distribution (bottom row). $Y$ axes denote the number of $\mathrm{V}(\mathrm{D})$ ) sequences analyzed, representative of the total $\mathrm{CTD}^{+}$Bmem cells analyzed. (B) Sequences from CTD- Bmem cells were analyzed as in $\mathbf{A}$.

The IgG subclass distribution was analyzed for $\mathrm{CTD}^{+}$and $\mathrm{CTD}^{-}$Bmem cells (Figure 2, A and B). The relative abundance of each IgG subclass was IgG1 > IgG2 > IgG3 > IgG4 in the $\mathrm{CTD}^{+}$and the $\mathrm{CTD}^{-} \mathrm{Bmem}^{-}$ cell compartments. For each subject, there was no discernable difference in the relative numbers of each IgG subclass between the $\mathrm{CTD}^{+}$and the $\mathrm{CTD}^{-}$populations. These data, therefore, suggest an impediment to class switch among $\mathrm{CTD}^{+}$Bmem cells as compared with Bmem cells of other specificities. However, the conditions determining which subclasses are produced appear to be unaltered between $\mathrm{CTD}^{+}$and $\mathrm{CTD}^{-} \mathrm{Bmem}$ cells.

Similar Ig heavy and light chain variable gene usage in $C T D^{+}$and $C T D^{-}$Bmem. Repertoire analysis of Bmem cells following specific infections have revealed overrepresentation of select Ig heavy chain variable (IGHV) gene families (58). To understand if $C$. difficile skews the IGHV usage in the Bmem cell repertoire, we analyzed the heavy and light chain variable $(\mathrm{V})$ and joining $(\mathrm{J})$ gene usage for $\mathrm{CTD}^{+}$and $\mathrm{CTD}^{-}$Bmem cells. For the $\mathrm{CTD}^{+}$and $\mathrm{CTD}^{-}$Bmem cells of subjects 1008, 1009, and 1013 (Figure 3A), the IGHV3 gene family, and specifically the IGHV3-23 gene was the most frequently used. A detailed analysis of the V-J gene usage within the IGHV3 gene family confirmed that IGHJ4 was the most prevalent IGHJ gene used by $\mathrm{CTD}^{+}$and $\mathrm{CTD}^{-}$Bmem cells (Figures $3 \mathrm{~B}$ and Supplemental Figure 4, A and B). For the light chain, it was observed that $\kappa$ was most frequently used, and the typical ratio of $\kappa$ to $\lambda$ usage (59) was evident (Figure 4, A and B). Genes V1 and V3 for $\kappa$ and V1, V2, and V3 for $\lambda$ were the predominant light chain $\mathrm{V}$ genes observed in the study (Figure 4, $\mathrm{C}$ and $\mathrm{D}$ ). Overall, the $\mathrm{V}$ gene usage of the $\mathrm{CTD}^{+}$Bmem cells was similar to that observed in $\mathrm{CTD}^{-}$Bmem cells. Furthermore, the IGHV gene usage was similar in subjects 1008,1009 , and 1013 .

Somatic hypermutation in class-switched $C T D^{+}$Bmem. Mutated $\mathrm{V}(\mathrm{D}) \mathrm{J}$ regions are a hallmark of antigen-experienced $\mathrm{B}$ cells. While the recombination of $\mathrm{V}, \mathrm{D}$, and $\mathrm{J}$ genes create a large repertoire of $\mathrm{B}$ cell receptors, the somatic mutations in $\mathrm{V}$ regions add further specificity and allow for affinity maturation. In the present study, the IGHV sequences from subjects 1008, 1009, and 1013 were compared with germline sequences to measure the frequency of somatic hypermutation in the $\mathrm{V}$ region (Figure 5). As expected, the class-switched sequences (IgA and $\mathrm{IgG}$ ) from both $\mathrm{CTD}^{+}$and $\mathrm{CTD}^{-} \mathrm{Bmem}$ had higher frequencies of mutations than the $\mathrm{IgM}^{+}$sequences. This was the case for replacement mutations that caused amino acid changes and silent mutations that did not cause amino acid changes. However, IgM sequences also had replacement mutations. Furthermore, the complementarity-determining regions (CDRs) of the class-switched sequences from the $\mathrm{CTD}^{+}$ and $\mathrm{CTD}^{-} \mathrm{Bmem}$ cells were more frequently mutated than the framework regions (FR) (data not shown). 
A
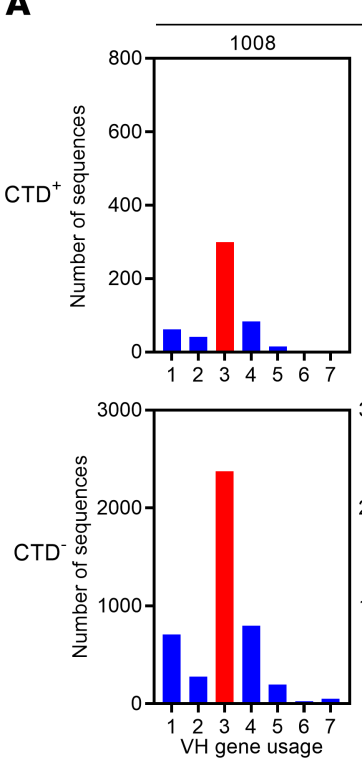

Subject
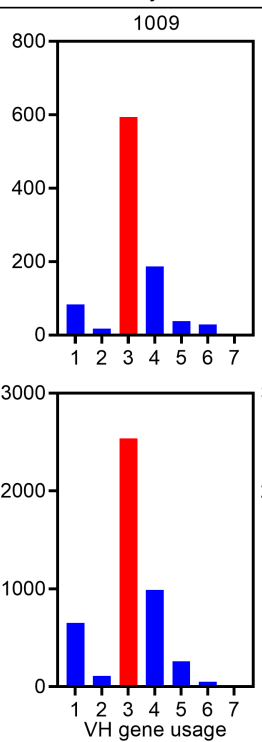
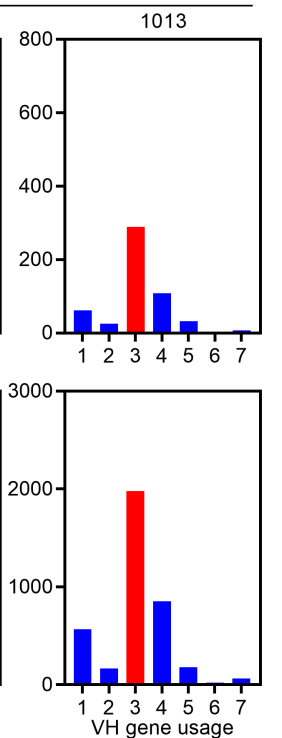

B
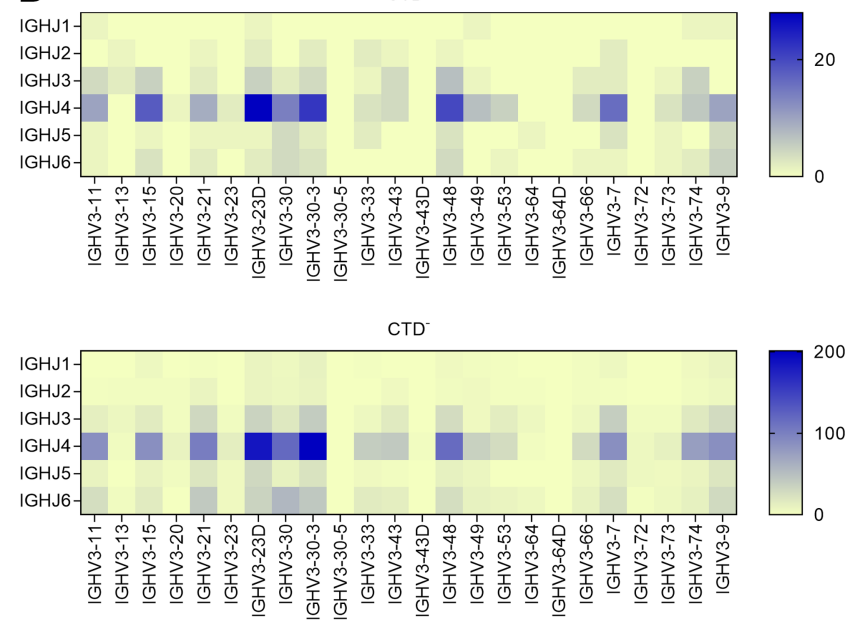

Figure 3. V gene usage in the Ig heavy chain. (A) Depicts the V gene usage of CTD+ (top row) and CTD- (bottom row) Bmem cells from each subject. IgM, IgG, and IgA sequences were included in the analysis. (B) Heatmaps depict the heavy chain V-J gene recombination pairs within the VH3 gene family. Sequences from the CTD+ Bmem cells (top panel) and from CTD- Bmem cells (bottom panel) are shown. Data shown are from subject 1008. The color scale indicates the frequency of occurrence of each VH3-J pair.

CDRs accumulate more replacement mutations than FRs, allowing CDRs to be more plastic and antigen responsive than the FRs that are tasked with maintaining Ab structure $(60,61)$. These findings indicated that the $\mathrm{CTD}^{+}$Bmem-encoded Abs were not likely to be deficient in affinity maturation and that some degree of affinity maturation was evident in the IgM compartment.

Similar characteristics of IgG1-switched CTD ${ }^{+}$and $C T D^{-}$Bmem. Anti-TcdB IgG is the best known correlate of protection against CDI and recurrence $(37,42-45)$. IgG1 was the predominant IgG subclass observed among $\mathrm{IgG}^{+} \mathrm{CTD}^{+}$Bmem cells and was analyzed in further detail (Figure 6). For all 3 subjects, the heavy $\mathrm{V}$ chain 3 (VH3) was the most used IGHV gene family for IgG1 sequences from CTD ${ }^{+}$and $\mathrm{CTD}^{-} \mathrm{Bmem}^{\mathrm{V}}$ (Figure 6, top). VH1 and VH4 were the next most frequently used genes. Bmem-encoded Abs were characterized by mutated sequences, and the number of IgG1 sequences that had 0-50 replacement mutations in their $\mathrm{V}$ region was analyzed (Figure 6, middle). A majority of the sequences had 11-20 replacement mutations in their IGHV regions (consisting of the FR1, FR2, FR3, CDR1, and CDR2 combined). Most of those replacement mutations were in the CDR1 and CDR2 regions (data not shown).

Addition and deletion of nucleotides during $\mathrm{V}(\mathrm{D}) \mathrm{J}$ recombination renders the antigen-binding CDR3 loop heterogeneous (62). Therefore, the range of CDR3 amino acid length in the IgG1 sequences of $\mathrm{CTD}^{+}$and $\mathrm{CTD}^{-}$Bmem cells was determined. More than $50 \%$ of the sequences had CDR3 lengths in the 10-20 amino acid range (Figure 6, bottom). Up to 4\% had CDR3 lengths of less than 10 amino acids. Only 9\%-10\% IgG1 sequences from the CTD ${ }^{-}$subset of all 3 individuals had CDR3 lengths of $>$ 20 amino acids. Sequences with CDR3 lengths of $>20$ amino acids in the CTD ${ }^{+}$subset had frequencies of $15 \%$ in subject $1008,21 \%$ in 1009 , and $9 \%$ in 1013 . The CTD ${ }^{+}$IgG1 sequences in the present study, therefore, displayed features characteristic of an antigen-experienced repertoire.

Clonal expansion of CTD-specific IgM antibody. The human Bmem cell compartment is characterized by a high degree of clonal diversity (63). The clonal families observed in class-switched and non-class-switched $\mathrm{CTD}^{+}$and $\mathrm{CTD}^{-}$Bmem cells from subjects 1008, 1009, and 1013 were therefore analyzed. A majority of the $\mathrm{CTD}^{+}$and $\mathrm{CTD}^{-}$Bmem populations were polyclonal, containing sequences unique within the cell sample analyzed (Figure 7). $\operatorname{IgM}^{+}$Bmem cells demonstrated several expanded clones. One $\mathrm{CTD}^{+} \mathrm{Bmem}$ clone from subject 1009 had 11 members, while a CTD Bmem clone from subject 1013 had 37 members (Figure 7).

Class-switched Bmem cells largely consisted of unique clones. All $\mathrm{IgA}^{+}$clones were unique except for 1 clone with 2 members (in $\mathrm{CTD}^{+}$Bmem of subjects 1008 and 1009). The $\mathrm{IgG}^{+}$clones in $\mathrm{CTD}^{+} \mathrm{Bmem}$ from subjects 1008 and 1009 were unique. Subject 1013 had $1 \mathrm{IgA}^{+}$clone with 4 members and 1 IgG $^{+}$clone with 2 members. Furthermore, clones identified from each subject were unique to that individual. 
A

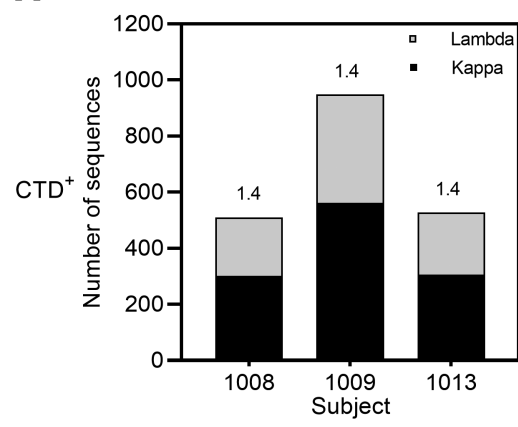

B

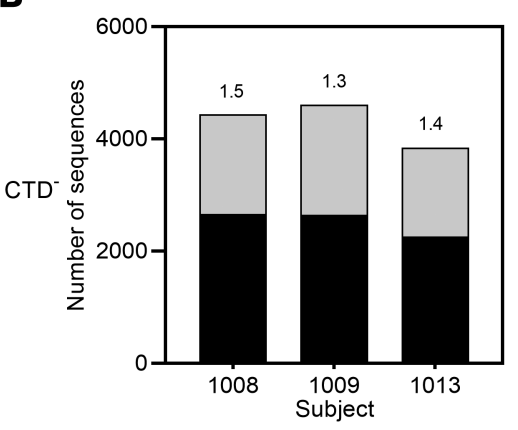

C

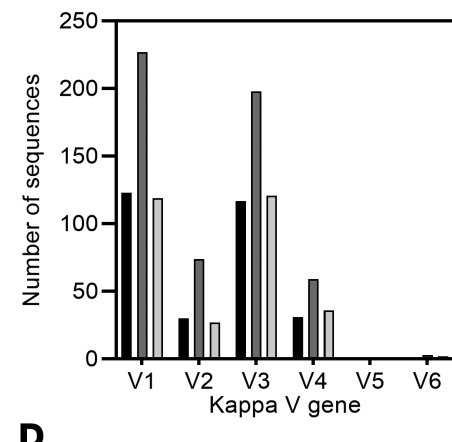

D

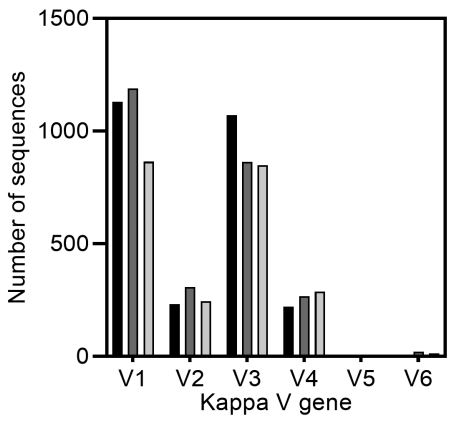

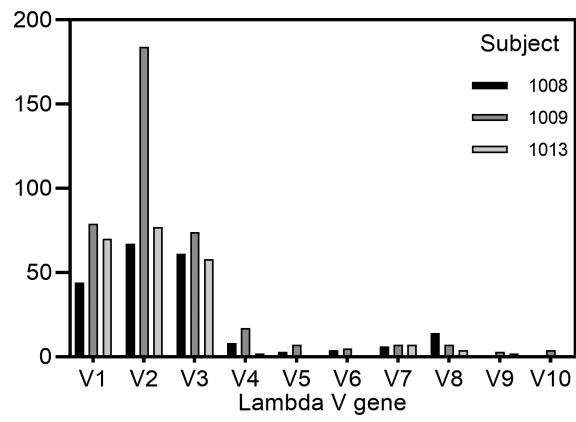

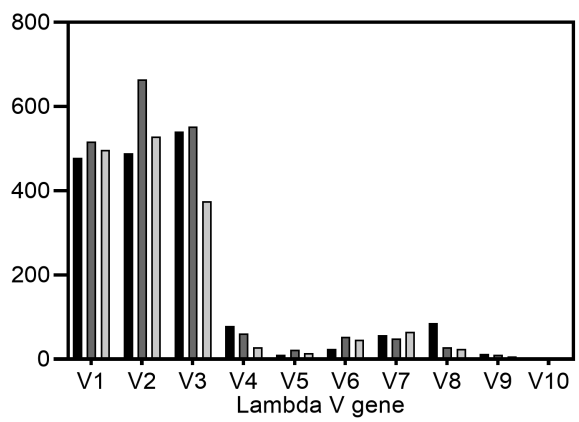

Figure 4. Light chain distribution and their $\mathbf{V}$ gene usage in $\mathbf{C T D}^{+}$and $\mathbf{C T D}^{-}$Bmem cells. (A) Depicts the number of $\mathrm{CTD}^{+} B$ mem cells expressing a $\kappa$ or a $\lambda$ light chain. Numbers above bars denote the $\kappa / \lambda$ ratio. (B) As in $\mathbf{A}$, but depicts $\kappa / \lambda$ ratio for CTD $^{-}$Bmem cells. (C) The frequency and distribution of $V$ gene usage by the $\kappa$ (left) and $\lambda$ (right) chains by CTD+ Bmem is shown. (D) As in C, but depicts light chain V gene usage by the CTD- Bmem cells.

The $\mathrm{CTD}^{-}$Bmem cells from the 3 subjects demonstrated limited clonal expansion in the $\mathrm{IgA}^{+}$Bmem cell compartment (ranging from 38 clones with 2 members to 1 clone with 7 members). Similarly, in the $\mathrm{IgG}^{+} \mathrm{Bmem}$ cell compartment, there was a range of 52 clones with 2 members to 1 clone with 4 members (data not shown).

While there was evidence of clonal expansion in $\mathrm{CTD}^{+} \mathrm{Bmem}$ cells, the expansion was largely restricted to a few IgM+ ${ }^{+}$clones, suggesting that $\mathrm{CDI}$ may result in a Bmem cell compartment composed of several unique clones.

Validation of sequencing and analytical strategy using Bmem cells from a healthy control. Validation of the barcoding, sequencing and analytical methods used in this study was provided by analyzing total Bmem cells from a healthy control (subject 1007) (Supplemental Figures 5 and 6). Enriched B cells were harvested and $\mathrm{CD}^{-} \mathrm{CD} 19^{+} \mathrm{CD} 20^{+} \mathrm{CD} 27^{+} \mathrm{CD} 38^{-} \mathrm{IgM}^{+}$and $\mathrm{CD} 3{ }^{-} \mathrm{CD} 19^{+} \mathrm{CD} 20^{+} \mathrm{CD} 27^{+} \mathrm{CD} 38^{-} \mathrm{IgM}^{-} \mathrm{Bmem}$ cells were sorted for heavy chain V; diversity (D); and J, light chain V, and J repertoire analysis (Supplemental Figure 5A). The healthy IgG subclass distribution (Supplemental Figure 5B), the V region usage (Supplemental Figure 5C), and the mutation frequency in IgA, IgG, and IgM (Supplemental Figure 5D) were as expected. Further analysis of the mutation frequency in IgG1 ${ }^{+}$Bmem cells (Supplemental Figure 6A), the CDR3 length (Supplemental Figure 6B), and the clonality of the IgM, IgG, and IgA compartments (Supplemental Figure 6C) were also as expected. These features were characteristic of a Bmem cell compartment and served to provide validation for the methods described in analysis of the Bmem repertoire from experimental subjects.

Characteristics and functional capacity of fully human full-length anti-CTD Abs. The best known correlate of protection against primary and recurrent CDI is TcdB-neutralizing IgG of potentially high affinity (37, $42-45,50,51)$. Experiments were therefore performed to test the antigen binding and functional activity of the IgG1 sequences that were observed in the $\mathrm{CTD}^{+} \mathrm{Bmem}$ cell compartment. Several mAbs were generated from the IgG1 sequences obtained from subjects 1008, 1009, and 1013. The sequences were selected to represent the VH gene usage, range of CDR3 lengths, and numbers of mutations in the $\mathrm{CTD}^{+} \mathrm{IgG} 1^{+}$ Bmem sequences (Supplemental Table 2). The mAbs were tested for antigen binding and affinity (Figure 8 and Figure 9). Of the mAbs generated, 24 of 49 bound by ELISA to CTD from TcdB1 and 22 of $49 \mathrm{mAbs}$ bound to CTD from TcdB2 (Figure 8). One of the $6 \mathrm{mAbs}$ tested (mAb 1009_17) bound both TcdB1-CTD and TcdB2-CTD with a less-than-nanomolar affinity (Figure 9). mAb 1009_17 bound TcdB1-CTD with dissociation constants $\left(K_{D}\right)=0.37 \pm 0.14 \mathrm{nM}$ and TcdB2-CTD with $K_{D}=0.108 \pm 0.02 \mathrm{nM}$. Saturated 
A CTD $^{+}$

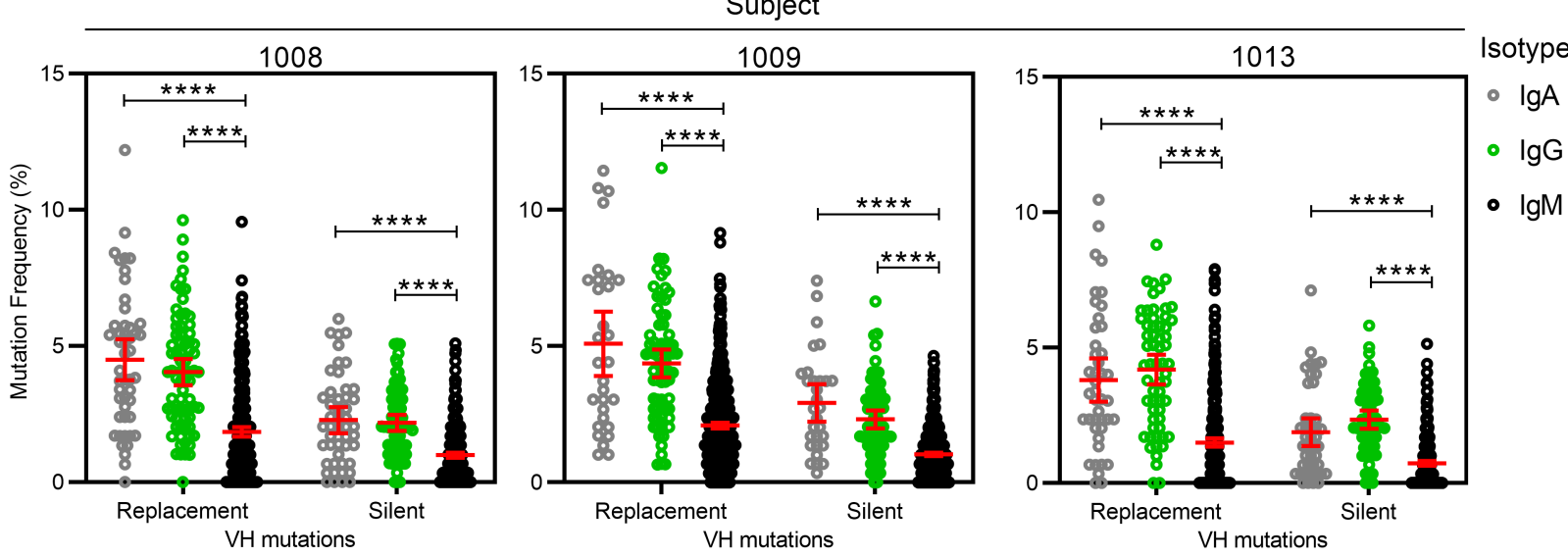

B $\mathrm{CTD}^{-}$

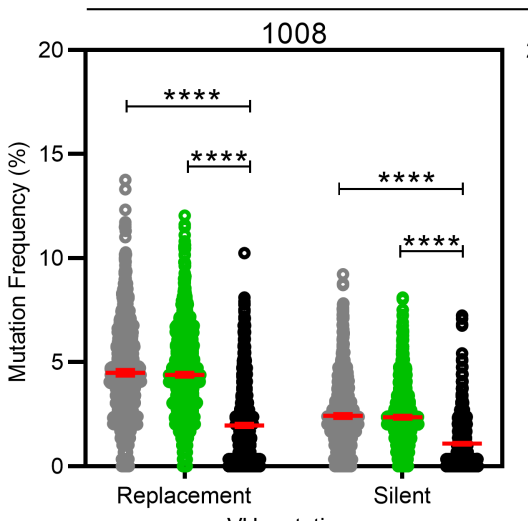

$\mathrm{VH}$ mutations

Subject
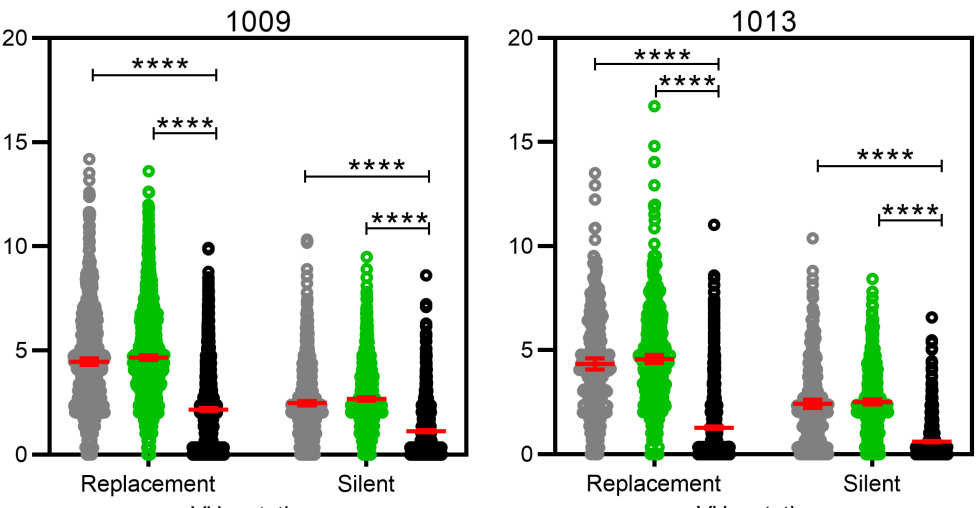

$\mathrm{VH}$ mutations

$\mathrm{VH}$ mutations

Figure 5. Somatic hypermutation in $\mathbf{C T D}^{+}$and $\mathbf{C T D}^{-}$Bmem cells. (A) Depicts the percent nucleotide mutations as compared with germline. Replacement mutations resulting in an amino acid change and silent mutations resulting in no amino acid change in the heavy chain $\mathrm{V}$ regions of IgA, IgG, and IgM sequences from CTD+ Bmem cells are presented. (B) Is as in A, but depicts CTD- Bmem cells. A Kruskal-Wallis test with Dunn's post hoc test correction was used to determine statistical significance in differences between mutation frequencies observed in each Ab isotype $\left({ }^{* * *} P<0.0001\right)$.

binding could not be achieved for all mAbs, consistent with low to moderate affinity, and are designated in the figure as approximate $(\sim)$ values.

The Bmem-encoded mAbs from the 3 subjects were then tested for their ability to neutralize in vitro intoxication of $\mathrm{CHO}$ cells by TcdB1 and TcdB2 (Figure 10). The mAbs from 1008, 1009, and 1013 tested individually or in a variety of combinations were unable to neutralize TcdB1 activity in vitro. However, mAb 1009_17 was able neutralize TcdB2 activity in vitro, resulting in $\sim 60 \%$ CHO cell viability (Figure 10, A and C).

$\mathrm{CTD}^{+} \operatorname{IgG} 1^{+}$Bmem cells lacked clonal expansion and encoded $\mathrm{mAbs}$ with limited toxin-neutralizing capacity. We therefore selected sequences from the clonally expanded $\mathrm{IgM}^{+} \mathrm{CTD}^{+} \mathrm{Bmem}$ cells of subjects 1008, 1009, and 1013 (Supplemental Table 2). The IgM V(D)J regions were expressed as IgG1 mAbs to control for differences between IgM and IgG1 constant regions. The IgM-V(D)J/IgG1 mAbs were then tested for antigen binding and toxin neutralization activity in vitro (Supplemental Figure 7). Only 2 of $8 \mathrm{mAbs}$ generated showed binding to TcdB1-CTD by ELISA. None of the mAbs demonstrated TcdB1 neutralization in vitro.

Plasma obtained from subjects 1008 and 1013, but not 1009, was able to neutralize both TcdB1 and TcdB2 in vitro. To confirm that the IgG in the plasma was primarily responsible for the neutralization, we depleted IgG from the plasma of subjects 1008 and 1013 and observed that the samples lost their capacity to neutralize toxin in vitro (Figure 10, B and D). CDI therefore resulted in generation of a toxin-specific plasma cell-derived polyclonal $\mathrm{Ab}$ pool containing sufficient amounts of neutralizing $\mathrm{Ab}$ for in vitro toxin neutralization. 
A $\mathrm{CTD}^{+}$
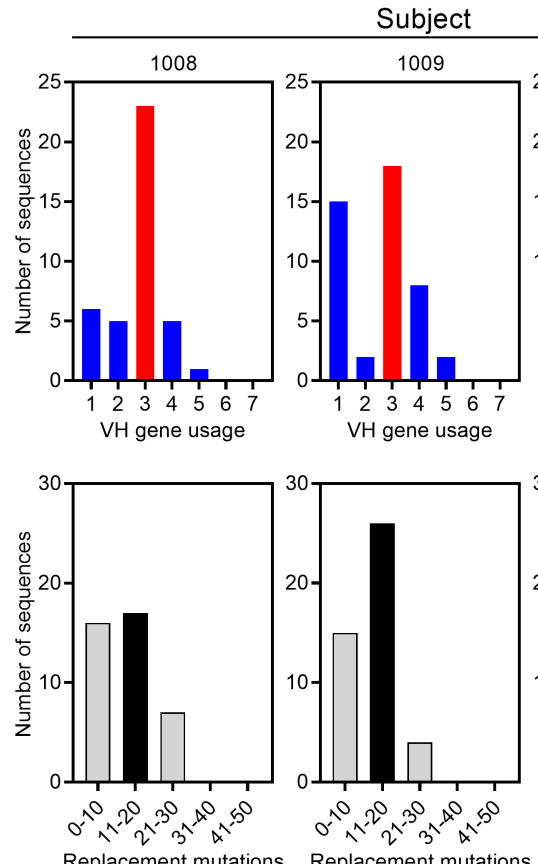

Replacement mutations
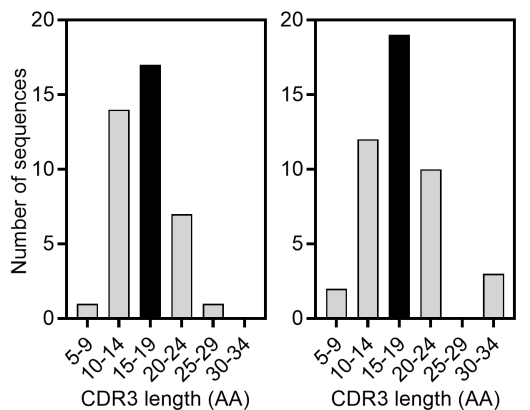
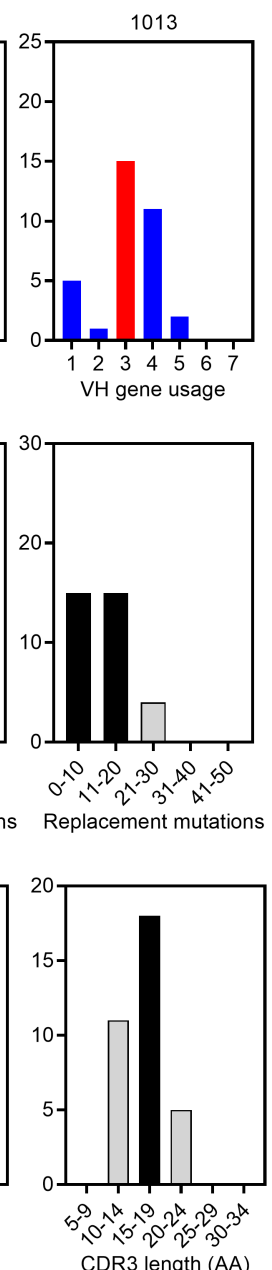

B CTD

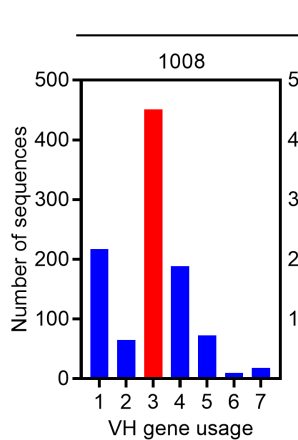

Subject
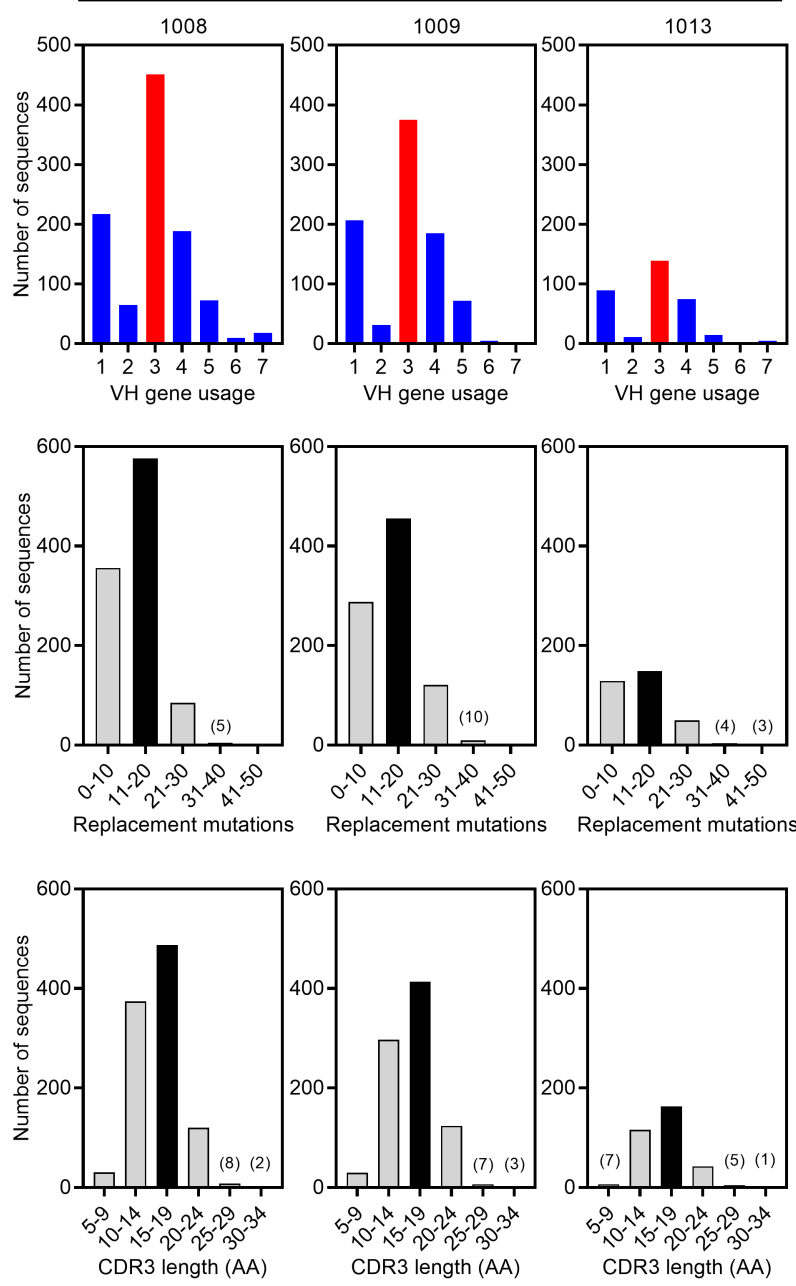

Figure 6. Heavy chain V gene usage, somatic hypermutation and CDR3 length in IgG1+ Bmem cells. (A) Depicts $V$ gene family usage (top), number of replacement mutations (middle), and CDR3 amino acid (AA) length (bottom) for the CTD+ Bmem IgG1 heavy chain sequences. (B) As in $\mathbf{A}$, but depicts IgG1 heavy chain sequences from CTD`- Bmem cells.

\section{Discussion}

Typically, the host immune system establishes "memory" to a primary infection, resulting in a rapid and effective response upon reexposure to a pathogen. A recent study from our laboratory revealed that an initial infection of mice with $C$. difficile spores did not induce a CTD/TcdB-specific Bmem response or protect from pathology associated with repeat infection (64). This is consistent with another study from our laboratory where human subjects with a history of CDI demonstrated poor differentiation of CTD-specific Bmem cells into new plasmablasts following polyclonal stimulation (33). Recurrent CDI could therefore result from an inadequate Bmem cell response. Studies with human subjects have shown that neutralizing serum IgG specific for TcdB is associated with protection against primary and recurrent infections $(42,43)$. However, the human TcdB-specific Bmem repertoire and whether it encodes TcdB-neutralizing Ab has not been evaluated. This is the first study, to the best of our knowledge, that determined the repertoire and function of $\mathrm{CTD}^{+} \mathrm{Bmem}$ from individuals with a self-reported history of $\mathrm{CDI}$.

Antigen-specific Bmem cells occur in low frequencies in human PBMCs. We therefore isolated TcdB1$\mathrm{CTD}^{+}$and $-\mathrm{CTD}^{-} \mathrm{Bmem}$ cells, single-cell barcoded them, and then examined their Ig genes by deep sequencing. Surprisingly, the $\mathrm{CTD}^{+}$Bmem cells had a much lower proportion of class-switched Abs than the $\mathrm{CTD}^{-} \mathrm{Bmem}^{-}$ cell population. These $\mathrm{IgM}^{+}$sequences from the $\mathrm{CTD}^{+} \mathrm{Bmem}$ cells had undergone somatic hypermutation, as evidenced by changes compared with germline sequences. The presence of mutations in the IgM sequences in conjunction with our cell-sorting strategy, which excluded $\mathrm{CD} 38^{+}$cells, confirmed that these were not natural 
A

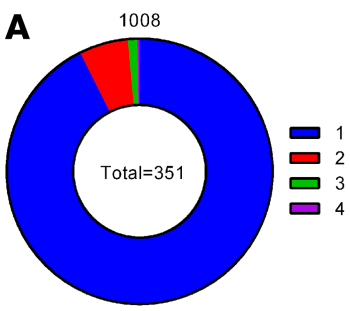

B

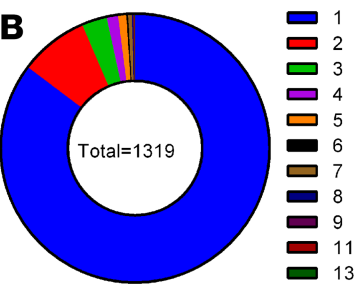

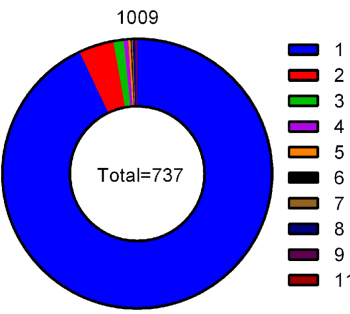
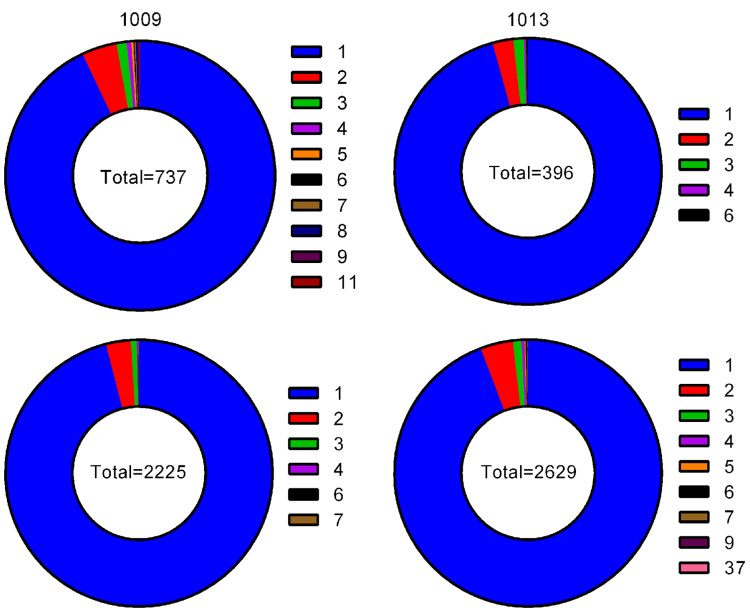

Figure 7. Clonal expansion in IgM+ $\mathbf{B m e m}$ cells. (A and $\mathbf{B})$ Graphs depict the clonal expansion in $\operatorname{lgM}^{+}$sequences from $\mathrm{CTD}^{+}(\mathbf{A})$ and $\mathrm{CTD}^{-}$(B) Bmem cells. The number in the center of each chart denotes the number of sequences analyzed. The numbers in the legends to the right of each chart indicate the size of a given clone. The shaded areas represent the frequency with which clones of each size appeared within the total sample.

$\mathrm{Ab}$-secreting cells (65). We observed a much higher frequency of $\mathrm{IgM}^{+}$rather than $\mathrm{IgG}^{+} \mathrm{CTD}^{+} \mathrm{Bmem}$ cells in our ELISPOT assays, as well. These findings are consistent with our observation of limited class switch and IgM dominance in our recently published study using a mouse model of $C$. difficile recurrence (64).

$\mathrm{IgM}^{+} \mathrm{Bmem}$ cells have been observed in human PBMCs in response to T-independent antigens such as polysaccharides (66) and malaria infection (67). To the best of our knowledge, this is the first report demonstrating a predominantly IgM ${ }^{+}$Bmem cell compartment following CDI. Several of the $\mathrm{CTD}^{+} \mathrm{IgM}_{\text {sequenc- }}$ es were clonally related, forming clones with up to 11 members. Recent studies have described IgM that can neutralize Chikungunya virus early in infection (68), that can block HIV-transmission in cervico-vaginal tissues (69), and that can afford protection against Influenza (70). However, we observed that the $\mathrm{CTD}^{+} \mathrm{IgM}^{+}$ Bmem cell-encoded Ab did not neutralize TcdB1-CTD. We did not anticipate Bmem-encoded CTD-specific IgM to play a role in neutralizing toxin, since there are several studies that have demonstrated IgG to be the best correlate of protection to CDI $(37,42-45)$. Furthermore, the IgG-depleted plasma samples in our study were unable to neutralize toxin in vitro, emphasizing the role of IgG in preventing recurrent $C D I$.

Analysis of IGHV gene usage in adults with rotavirus-experienced B cells show bias in their use of the $\mathrm{VH} 1$ and $\mathrm{VH} 4$ genes (71). $\mathrm{VH}$ analysis in B cells from individuals with autoimmune disease have demonstrated VH4 and VH5 biases in systemic lupus erythematosus (SLE) and VH3 bias in myasthenia gravis (72). To understand if CDI resulted in a biased VH repertoire, we analyzed the $\mathrm{VH}$ gene usage of $\mathrm{CTD}^{+}$ and $\mathrm{CTD}^{-} \mathrm{Bmem}$ cells and found no differences between them. Consistent with previous studies involving healthy individuals, we observed that the V3 and J4 gene families dominated the heavy chain repertoire (73-75). The IGHV regions from class-switched $\mathrm{CTD}^{+} \mathrm{Bmem}$ cells, from $\mathrm{CTD}^{+} \mathrm{IgM}^{+} \mathrm{Bmem}$ cells, and from $\mathrm{CTD}^{-}$Bmem cells had undergone somatic hypermutation. This demonstrates that the affinity maturation process in patients was intact.

The ratio of replacement to silent mutations in the CDR1 and -2 regions of several class-switched sequences from $\mathrm{CTD}^{+}$Bmem cells was $>2.9$, suggesting antigenic selection of those clones (76). Although IgG only accounted for about $10 \%$ of the $\mathrm{CTD}^{+} \mathrm{Bmem}$ cells, the subclass distribution was similar to that observed for the $\mathrm{CTD}^{-}$Bmem cells, with IgG1 accounting for a majority of the $\operatorname{IgG}^{+}$sequences. As is typical for class-switched Bmem cells, the IgG1 sequences had CDR3 lengths of up to 20 amino acids and an increased VH1 usage as compared with memory IgM sequences (77). Overall, these findings suggested that the $\mathrm{CTD}^{+}$Bmem cells encoded a repertoire that was theoretically capable of neutralizing TcdB. For this reason, several IgG1 mAbs were generated from the sequences obtained from each subject to test their binding specificity to and their affinity for CTD from TcdB1 and TcdB2. We also tested the ability of these IgG1 mAbs to neutralize TcdB1 and TcdB2 in an in vitro $\mathrm{CHO}$ cell viability assay. While almost $50 \%$ of the 49 IgG1 mAbs generated bound CTD by ELISA, only $1 \mathrm{mAb}$ (mAb 1009_17) bound with high affinity $\left(K_{D}\right.$ $=0.108 \pm 0.02 \mathrm{nM}$ ) and neutralized TcdB2 to prevent $\mathrm{CHO}$ cell killing in vitro. This supports the possibility 
A

TcdB1-CTD
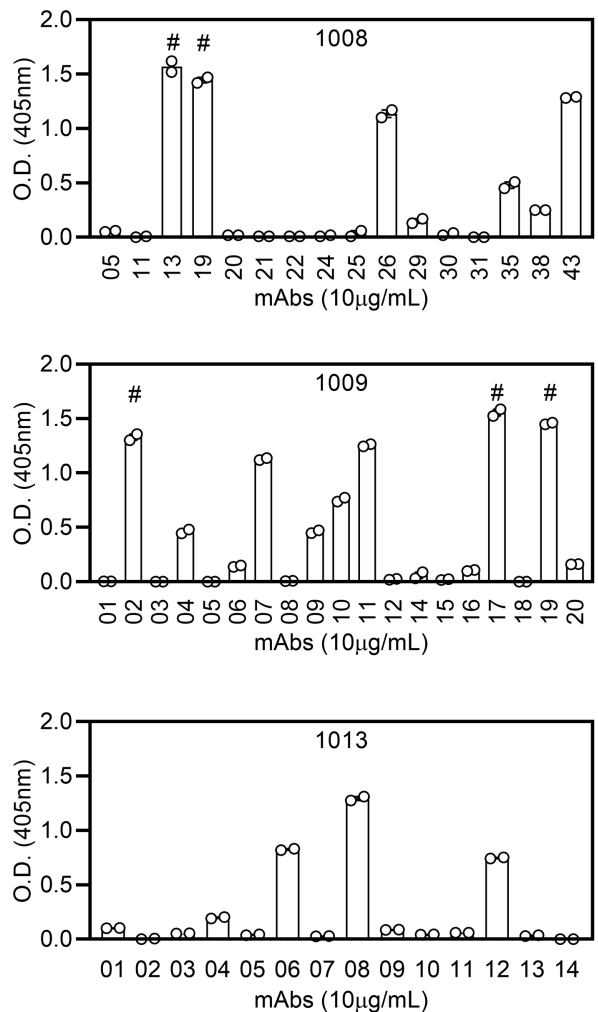

B
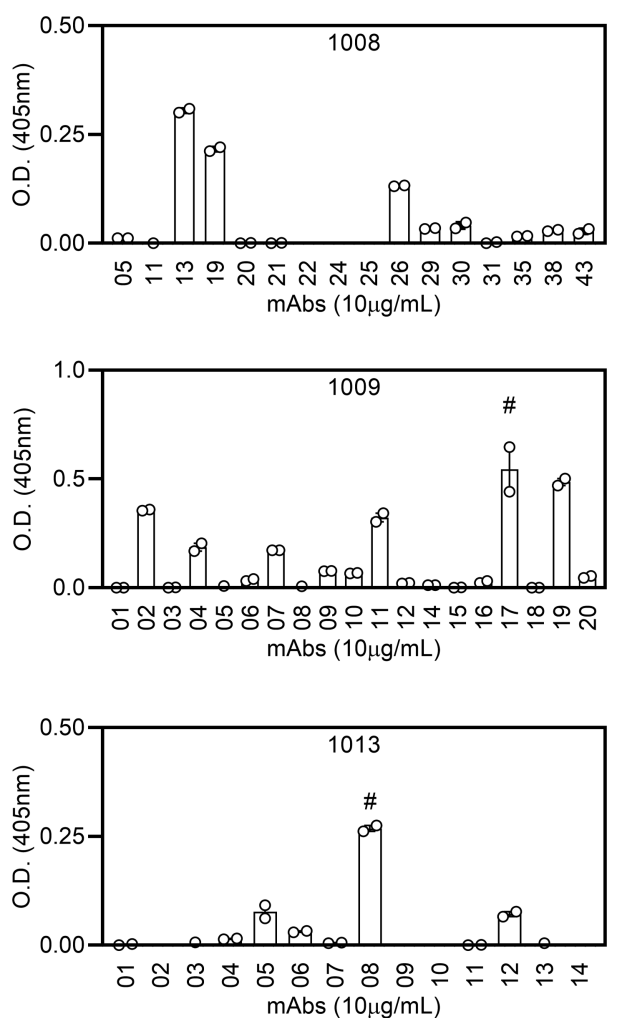

Figure 8. Bmem-encoded mAbs bind the CTD region of TcdB1 and TcdB2. Select IgG1 heavy and light chain sequences from CTD+ Bmem cells were cloned and transfected into HEK293 cells to generate physiologically paired, full-length human mAbs. (A) TcdB1-CTD binding by mAbs from subjects 1008 (top), 1009 (middle), and 1013 (bottom) were tested by ELISA. The symbol (\#) above a bar indicates the mAbs that were analyzed for CTD-binding affinity. Duplicates from a single experiment are presented and are representative of at least 2 independent determinations. (B) As in $\mathbf{A}$, except TcdB2-CTD binding was analyzed. The data are represented by mean \pm SEM.

that CTD-specific Bmem cells encode mostly low-affinity Abs incapable of toxin neutralization. Bezlotoxumab, a TcdB-targeting human mAb FDA-approved only for prevention of recurrent CDI $(78,79)$, binds high-affinity sites in the full-length TcdB1 with a $K_{D}$ of $19 \pm 5 \mathrm{pM}$ (49). This $K_{D}$ is 19-fold greater than the $K_{D}$ with which the highest-affinity $\mathrm{mAb}$ expressed in this study binds TcdB1 (mAb 1009_17; $K_{D}=0.37 \pm$ $0.14 \mathrm{nM}$ ). While the CTD binding site for bezlotoxumab has been characterized (49), the specific binding sites for the mAbs generated in this study remain to be identified.

It should be noted that although CTD-binding and toxin-neutralizing Bmem cell-encoded mAbs were generated for this study, the question remains as to whether these Bmem cells have the capacity to differentiate in response to CDI and express Abs in vivo. This is attested by the inability of plasma from subject 1009 to neutralize toxin in vitro, although their Bmem cell compartment encoded a toxin-neutralizing $\mathrm{mAb}$. In our recent murine studies, $\mathrm{CDI}$ resulted in a poor expansion of $\mathrm{PD}-\mathrm{h}^{\mathrm{hi}} \mathrm{CXCR} 5^{+}$follicular helper $\mathrm{T}$ cells ( $\mathrm{Tfh}$ ) (64). This lack of $\mathrm{T}$ cell help could limit Bmem cell expansion and differentiation into $\mathrm{Ab}$-secreting plasma cells. The role of Tfh in this study could not be explored, since the subject samples were obtained several months after infection.

It is also possible that CTD-specific Bmem cells encode low-affinity Abs incapable of toxin neutralization. This is supported by the mostly low- to moderate-affinity mAbs produced from the CTD-specific Bmem cell pool in the present study and the observation that the only mAb (mAb 1009_17) that bound TcdB2-CTD with high affinity also successfully neutralized TcdB2 in an in vitro viability assay.

Differences in disease severity could also influence the Bmem response. Although subjects 1008, 1009, and 1013 self-reported a single infection in the 5 years before recruitment into this study, they all reported being symptomatic. Subjects 1008 and 1013 reported receiving medical treatment, and only 1013 reported being hospitalized due to CDI. Due to the lack of complete medical history, we cannot comment on the influence 
A

TcdB1-CTD

1008

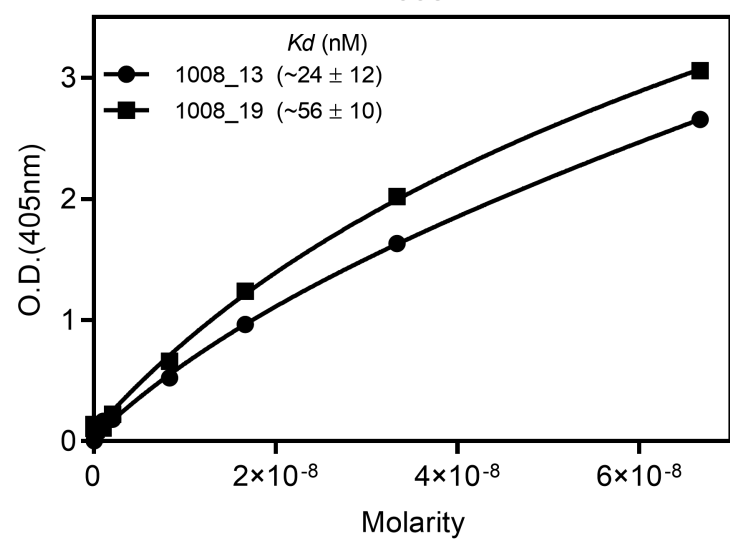

1009

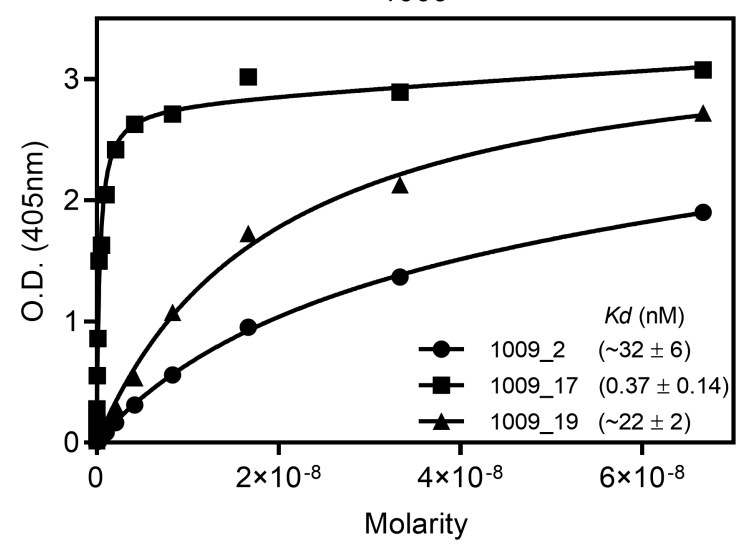

B

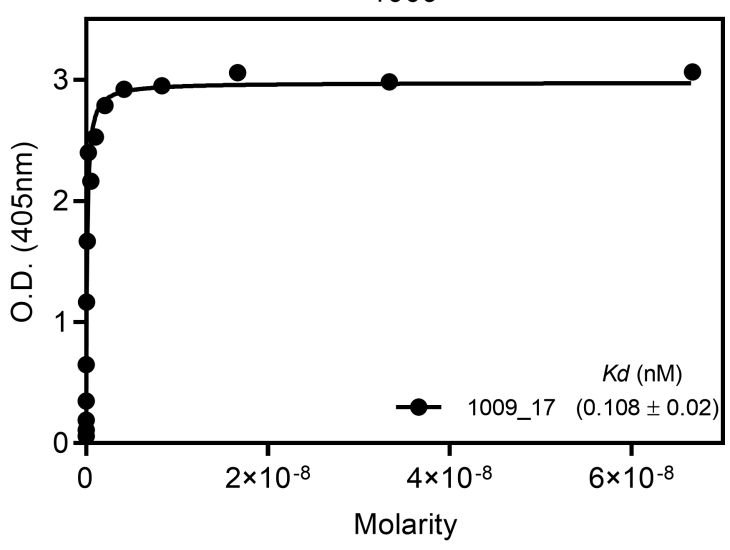

1013

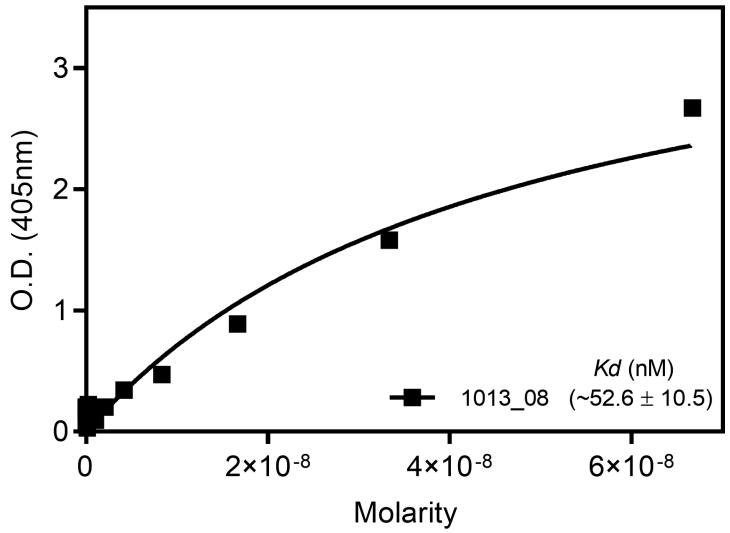

Figure 9. Bmem-encoded mAbs bind CTD with low to moderate affinity. (A) Select mAbs from subjects 1008 (top) and 1009 (bottom) were subjected to a 16-point dilution curve to calculate their binding constants $\left(K_{D}\right)$ to analyze their binding affinity to TcdB1-CTD. The $K_{D}$ values are as indicated. (B) As in A, except the binding affinity to TcdB2-CTD for select mAbs from subjects 1009 and 1013 was analyzed. Each experiment was performed at least 3 times with the same results.

of disease severity on the humoral response in our cohort. An alternative hypothesis is that Bmem-encoding neutralizing $\mathrm{Ab}$ may only develop after several recurrent infections, at which point the individual may not benefit from those Abs due to the extensive gut damage from previous infections. Comparing the Bmem cell repertoires in individuals following recurrent and nonrecurrent infections may allow testing of this hypothesis, but the high mortality rate in individuals with recurrent disease may preclude a larger study.

It is very likely the study participants could have been infected with a $C$. difficile strain other than the historical VPI-10463 strain; therefore, their Bmem-encoded Abs did not neutralize TcdB1. While Abs produced in response to TcdB2 from the hypervirulent NAP1/BI/027 strain cross-react with TcdB1 from the historical strain, the cross-neutralization between strains is limited $(28,33,80)$. This was confirmed in our analysis where $1 \mathrm{mAb}$ from subject 1009 bound CTD from both TcdB1 and TcdB2 but only neutralized TcdB2 in vitro. In this study, we tested the CTD-specific Bmem response, but the response to TcdB (whole toxin) could arguably be broader. However, we observed that the plasma anti-TcdB1-CTD IgG response was very similar to the anti-TcdB1 IgG response, and the same plasma samples had background level reactivity to a recombinant TcdB1 glucosyltransferase domain (data not shown). These findings, combined with previously published literature measuring the antigenicity and neutralizing capacity of CTD $(33,55,56)$, indicate a predominantly CTD-specific Bmem repertoire.

The lack of TcdB1 neutralization by the Bmem-encoded mAbs appeared to contrast with that of plasma samples from subjects 1008 and 1013, which neutralized toxin in an IgG-dependent manner. A discrepancy between plasma antibody titers and circulating Bmem cell frequency and function has been documented for $C$. difficile and other bacterial toxins and has been proposed as a feature of the host humoral response to bacterial toxins (54, 81). Although this study was not designed to investigate differences between Bmem and plasma cell-derived Abs, 
A

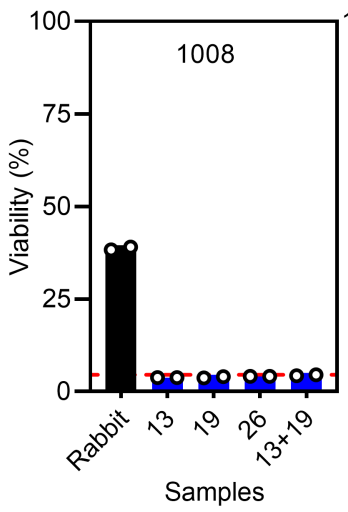

C

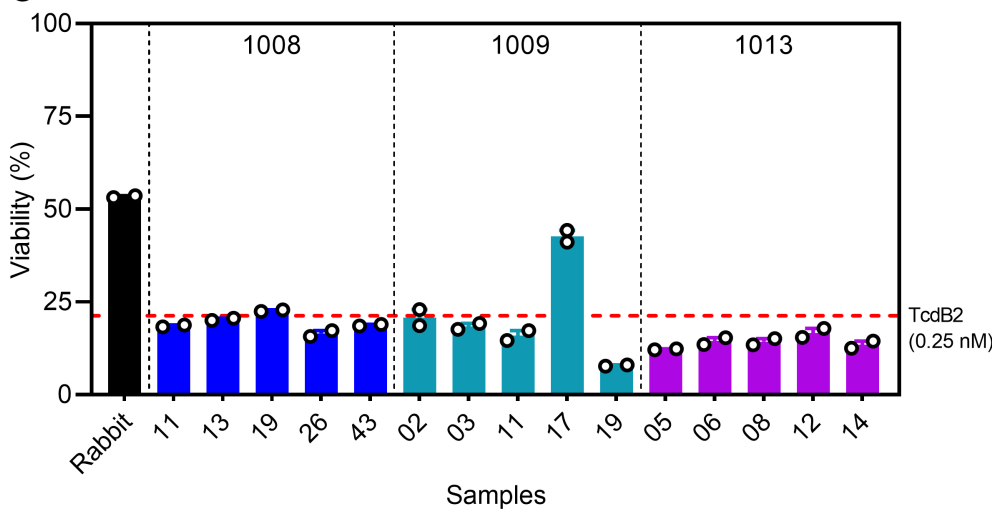

B

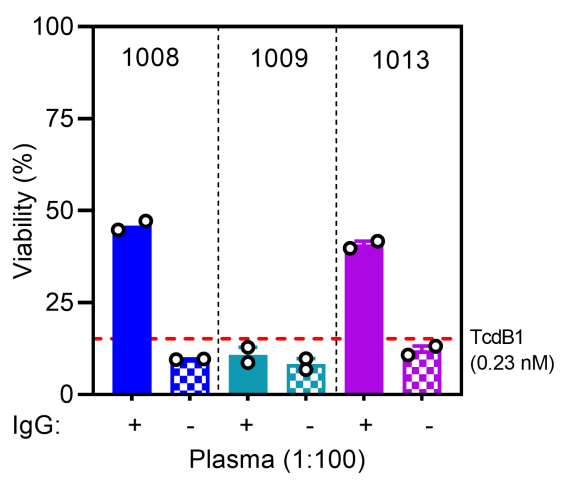

D

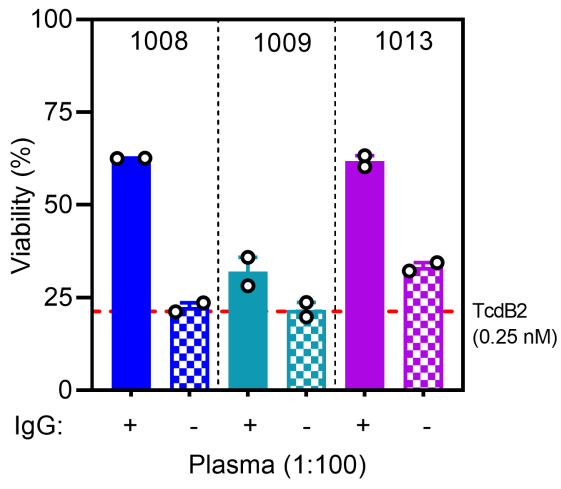

Figure 10. CTD-specific Bmem encode nonneutralizing antibodies. (A) Serum from CTD-immunized rabbit diluted to 1:100 and mAbs from subjects 1008, 1009 , and 1013 at a final concentration of $10 \mu \mathrm{g} / \mathrm{mL}$ mixed with media containing $0.23 \mathrm{nM}$ TcdB1 were added to CHO cells to assess cell viability. (B) IgC from plasma of subjects 1008, 1009, and 1013 was depleted and tested in vitro for toxin neutralization capacity. The plasma with and without IgC were diluted 1:100 in media with $0.23 \mathrm{nM}$ TcdB1. (C and D) As in A and B, respectively, except samples were mixed with media containing $0.25 \mathrm{nM}$ TcdB2 and added to CHO cells to assess cell viability. Red dotted line represents CHO cell viability in the presence of media containing toxin alone. Duplicates from a single experiment are presented and are representative of at least 2 independent determinations. The data are represented by mean \pm SEM.

there could be several explanations for this observation. Arguably, the simplest explanation is that only a small proportion of plasma cell-derived Abs are toxin neutralizing, but sufficient neutralizing Abs had accumulated in the sera to be functional in the in vitro assay. Similarly, very few Bmem cells may encode neutralizing $\mathrm{Ab}$, explaining why only $1 \mathrm{mAb}$ of 49 was neutralizing. The TcdB-neutralizing Ab observed in plasma samples is likely composed of numerous-fine specificities targeting several epitopes on the toxin, allowing more efficient toxin neutralization. Plasma from subjects 1008 and 1013 neutralized both TcdB1 and TcdB2 in vitro, possibly alluding to a requirement for combating CDI with Abs of multiple specificities. In this study, it was observed that several cocktails of 3 different Bmem cell-derived anti-CTD mAbs failed to neutralize toxin in vitro.

Finally, a caveat to extrapolating from in vitro toxin neutralization studies is that they may not accurately predict in vivo protection $(82,83)$. Toxin concentration and availability of neutralizing Abs in the gut lumen, as well as rate of toxin clearance, are likely to influence disease progression, severity, and treatment of $\operatorname{CDI}(26,84,85)$.

Several vaccine candidates to prevent CDI are in clinical trials, and while they show promise, their efficacy remains to be determined (86). Our study highlights the importance of considering the basic immune response to this infection, as well as the necessity of designing and testing new vaccines. In an animal model, immunization with CTD followed by CDI did not generate a recall response (64), and the animals were protected due to the $\mathrm{Ab}$ secreted by plasma cells generated in response to prior immunization. Similarly, this study demonstrated that CDI did not establish an efficient memory response in humans. This implies a requirement for repeated vaccinations to sustain an adequate protective response to future infections.

Further studies comparing Bmem cell repertoires in larger cohorts of individuals with single episodes of CDI or recurrent CDI will allow a deeper understanding of how $C$. difficile impacts the host humoral 
immune response. Comparing the plasma cell-derived $\mathrm{Ab}$ repertoire with that of the Bmem-derived $\mathrm{Ab}$ repertoire may provide further insights. Finally, the immune response to $C$. difficile antigens other than the toxin need to be evaluated.

\section{Methods}

Supplemental Methods are available online with this article.

Human subject eligibility, recruitment, and selection. The present study was designed to identify individuals with a history of CDI and determine their Bmem-encoded Ab repertoire. To achieve this goal, blood samples were collected from males and females who either had CDI within the past 5 years (subjects) or had no known history of CDI (controls). Individuals aged 20-85 and asymptomatic at the time of the blood draw were eligible for the study. Individuals with a history of major health issues including autoimmune disease, cancer, cardiovascular disease, or ongoing infectious disease (including HIV) were excluded from the study. Individuals who were presently unhealthy, had been vaccinated within the past month, or weighed less than 110 pounds were also excluded. Subjects included in this study self-reported receiving a laboratory-based diagnosis for CDI and reported no complications from CDI. Subjects 1008 and 1009 self-reported single episodes of CDI at the time of recruitment. Subject 1013 self-reported 2 episodes 3 years apart, with the first episode occurring almost 6 years before recruitment in this study, and was hospitalized due to the second episode. Since the second episode for subject 1013 did not occur within 12 weeks of the first infection, it did not meet the criteria for recurrent CDI (51). Blood samples were analyzed to determine if individuals had a detectable population of TcdB-specific (CTD fragment of TcdB) Bmem cells. Subjects 1008, 1009, and 1013 had demonstrable CTD-specific Bmem cells in peripheral blood as detailed in the Results and were available for a second visit to provide sample for repertoire analysis. Repertoire analysis was therefore performed on $\mathrm{CTD}^{+}$and $\mathrm{CTD}^{-}$Bmem cells from subjects 1008, 1009, and 1013. To validate our isolation, sequencing, and analytical methods, we isolated total Bmem cells from a healthy control (subject 1007) for repertoire analysis. Details for individuals included in this study are presented in Supplemental Table 1.

Sample procurement, PBMC preparation, and B cell enrichment. Peripheral venous blood was drawn from healthy subjects into vacuum tubes containing acid citrate dextrose (BD Biosciences). Samples were centrifuged for 15 minutes at $400 \mathrm{~g}$ at room temperature to collect plasma. Packed blood was mixed with an equal volume of $1 \times$ PBS, layered onto $15 \mathrm{~mL}$ of lymphocyte separation medium, known as LSM (Lonza), and centrifuged at $800 \mathrm{~g}$ (no brake) for 30 minutes at room temperature. PBMCs collected using a pipette were washed with PBS and resuspended in PBS containing 2\% v/v FCS. PBMCs were used for initial flow cytometry analysis. The RosetteSep Human B cell enrichment cocktail (Stemcell Technologies) was used for B cell enrichment according to the manufacturer's instructions. Briefly, whole blood was mixed with RosetteSep cocktail ( $50 \mu \mathrm{L} / \mathrm{mL}$ of blood sample) and allowed to incubate for 20 minutes at room temperature. The sample was then diluted by adding an equal volume of PBS $/ 2 \% \mathrm{v} / \mathrm{v}$ FCS. After mixing gently, the diluted sample was layered onto LSM and centrifuged at $1200 \mathrm{~g}$ (no brake) for 20 minutes at room temperature. The enriched B cell population was collected from the top of the LSM layer, washed in PBS, and resuspended in PBS $/ 2 \%$ $\mathrm{v} / \mathrm{v}$ FCS. The enriched B cell samples were used as starting material for Bmem cell labeling and sorting.

Flow cytometry and cell sorting. Where indicated, PBMCs or enriched B cells were incubated with flurochrome-conjugated $\mathrm{mAbs}$ against cell surface proteins at $4^{\circ} \mathrm{C}$ for 30 minutes, before washing 3 times with PBS containing 2\% FCS. The following anti-human mAbs were used: PE-Alexa Fluor 610 CD19 (clone SJ25C-1), Pacific Orange CD20 (clone HI47) APC-Alexa Fluor 750 CD27 (clone CLB-27/1), and APC-Cy5.5 CD38 (clone HIT2) from Invitrogen; PE-Cy7 CD3 (clone UCHT1) and APC IgG (clone G18-145) from BD Biosciences; and PE-IgM (clone UHB) from SouthernBiotech. Data were collected using a FACSAria III instrument and analyzed using FlowJo_V10 software (BD Biosciences). For Bmem cell isolation, enriched B cells were first selected for size and granularity using FSC/SSC followed by gating for singlets. The CD3-CD20 ${ }^{+} \mathrm{C}-$ $\mathrm{D} 19^{+} \mathrm{CD} 27^{+} \mathrm{CD} 38^{-}$cells were then selected to obtain Bmem cells. CD20 ${ }^{+} \mathrm{CD} 27^{+} \mathrm{CD} 43^{+} \mathrm{CD} 70^{-} \mathrm{CD} 38^{+} \mathrm{CD} 5^{+}$ B1 B cells were therefore not collected during sorting (65). Where indicated, cells were counterstained with Alexa 488-CTD to facilitate simultaneous sorting of $\mathrm{CTD}^{+}$and $\mathrm{CTD}^{-}$Bmem cells. B cell receptor blocking was achieved by adding $20 \mu \mathrm{L}$ goat anti-human IgG, IgM, and IgA (H\&L, catalog GWB-A3E324) from GenWay Biotech per $2 \times 10^{6} \mathrm{PBMCs}$. After a 30 -minute incubation at $4^{\circ} \mathrm{C}$, the samples are washed once with $\mathrm{PBS}$ containing $2 \%$ FCS before adding Alexa 488-CTD.

Expression and purification of $T c d B$ and CTD and CTD labeling. TcdB from strain VPI-10463 and NAP1/ BI/027 was purified using established methods $(28,87)$. The CTD-encoding region of the TcdB gene was 
codon optimized and cloned into the pET15b plasmid (GenScript) as described previously (33). Briefly, the VPI-10463 and NAP1/BI/027 CTD genes were amplified using primers 5'-GATCATATGCTGTATGTGGGTAACCG-3' and 5'-AACGGATCCTTATTCGCTAATAACCA-3', and restriction sites BamHI and NdeI were included for cloning into pET15b. VPI-10463 TcdB is referred to as TcdB1 and NAP1/BI/027 TcdB is referred to as TcdB2. VPI-10463 CTD (TcdB1 amino acids 1651-2366) and NAP1/BI/027 CTD (TcdB2 amino acids 1651-2366) were expressed in E. coli BL21 star DE3 (Invitrogen) and purified by Ni2 ${ }^{+}$ affinity chromatography (HisTrap; GE Life Sciences). The holotoxin and CTD are expressed and purified using the same method, and the structure of the CTD obtained maintains the same structure as the holotoxin (49). Mouse splenocytes were cultured with the CTD preparation, which failed to cause polyclonal B cell expansion and IgM secretion, as is expected for LPS, thus confirming sufficient LPS removal during purification. An Alexa Fluor 488 protein labeling kit (Invitrogen) was used to label CTD from TcdB1, according to the manufacturer's instructions.

Barcoding and library construction. Sorted $\mathrm{CTD}^{+}$and $\mathrm{CTD}^{-}$Bmem cells were processed using the Chromium Single Cell V(D)J Enrichment Kit for human B cells in conjunction with a Chromium controller. This was performed according to the manufacturer's instructions (10X Genomics) and as described previously (88). Briefly, each cell was partitioned, along with a single barcoded Gel Bead into an individual Gel Bead in Emulsion (GEM). Once the Gel Bead dissolved and the cell was lysed, a reverse transcription reaction allowed the cell to be individually and uniquely barcoded. The barcoded cDNA was then amplified with primers specific to Ig-constant regions, resulting in targeted enrichment of the V(D)J. The V(D)J enrichment kit included all reagents and primers for PCR amplification of the full-length variable and constant regions. This process resulted in a library of full-length Ig genes ready for next-generation sequencing.

Next-generation sequencing. The amplified transcripts were sequenced using a NovaSeq S1 System (Illumina) by the Oklahoma Medical Research Foundation Clinical Genomics Center. Libraries were sequenced to a depth of 200 million paired reads. The raw output files were processed using Cell Ranger 3.0.2 software (10X Genomics) to generate FASTA files for further analysis. For the CTD $\mathrm{Bmem}^{+}$cells, this resulted in 2262, 4394, and 1826 annotated heavy and light chain sequences for subjects 1008,1009 , and 1013 , respectively. For the $\mathrm{CTD}^{-}$Bmem cells, this resulted in 16684, 16009, and 15868 annotated sequences for subjects 1008,1009 , and 1013, respectively. These sequences were further curated for full-length, productive sequences that had a single heavy and light chain pair. This curation resulted in 506, 948, and 527 $\mathrm{CTD}^{+}$Bmem sequences and 4443, 4612, and $3845 \mathrm{CTD}^{-}$Bmem sequences used in this study for subjects 1008, 1009, and 1013, respectively. Difference in frequency of sequences between 1009 and other subjects was less than 2-fold for both $\mathrm{CTD}^{+}$and $\mathrm{CTD}^{-}$Bmem cells, allowing appropriate comparisons.

$R N A$-seq data analysis. The FASTA files were uploaded to the IMGT HighVQuest website (http://imgt. org/HighV-QUEST/home.action). Data from IMGT HighVQuest were parsed in RStudio (http://www. rstudio.com/) using MakeDb.py from Change-O (89). These data were then filtered to keep barcodes associated with sequences that were functional, full-length, and had only 1 heavy chain and light chain pair. Clones were defined and germlines assigned with DefineClones.py and CreateGermlines.py, respectively, from Change-O using the hamming distance algorithm. To assign clonally related sequences, a clustering threshold of $85 \%$ (CDR3 sequence similarity) was determined with distToNearest function and findThreshold function. Mutations in the heavy chain V regions were calculated using observedMutations function from the SHazaM R package (89).

Human $m A b$ synthesis. Genes for mAb generation were selected from the IgG1 sequences from $\mathrm{CTD}^{+}$ Bmem cells (Supplemental Table 2). To limit selection bias, sequences that spanned various heavy chain CDR3 lengths, numbers of $\mathrm{V}$ region mutations, and $\mathrm{V}$ region usage were included. The mAbs were generated using a previously published method (90), with the exception of using sequences generated using $10 \mathrm{X}$ Genomics technology rather than single-cell reverse transcription PCR (RT-PCR). To express mAbs from $\mathrm{CTD}^{+} \operatorname{IgM}{ }^{+}$Bmem cells from each subject, we selected sequences belonging to clonal families with several members (subject 1008, 4 members; 1009, 8, 9, and 11 members; 1013, 6 members). The heavy chain V region from these sequences were expressed with an IgG1 heavy chain constant region. After deep sequencing, heavy and light chain genes were synthesized by IDT (Integrated DNA Technologies). These genes were then cloned into separate heavy and light chain ( $\kappa$ or $\lambda$ as appropriate) vectors and transformed using DH5o competent cells (Invitrogen). Four colonies were picked from the transformation for mini-prep followed by sequencing. The sequences from each of the colonies were matched to the consensus, and the best match was moved forward to maxi-scale preparation. Human kidney epithelial cells (HEK293 cell line; ATCC) 
were transiently cotransfected with heavy and light chain vectors using polyethylenimine, and the cells were allowed to produce Abs over 5 days. Pierce Protein A agarose beads (Thermo Fisher Scientific) were used to purify the $\mathrm{mAb}$ from the cell culture supernatant. The mAbs were then analyzed for concentration, specificity, and biological activity.

ELISA. Maxisorp (Thermo Fisher Scientific) plates were coated with $100 \mu \mathrm{L} /$ well of CTD (10 $\mu \mathrm{g} / \mathrm{mL}$ ) diluted in carbonate coating buffer and incubated at $4^{\circ} \mathrm{C}$ overnight. After washing with PBS/0.05\%Tween-20, plates were blocked with $200 \mu \mathrm{L} /$ well PBS/0.05\%Tween-20/1\%BSA (blocking buffer) for 2 hours at room temperature. After washing the plates, $100 \mu \mathrm{L} /$ well of mAbs diluted $10 \mu \mathrm{g} / \mathrm{mL}$ in blocking buffer were added and allowed to incubate for 2 hours at room temperature. After 4 washes, HRP-anti human IgG (Jackson ImmunoResearch, 1:2500 in blocking buffer) was added to plates and incubated for 1 hour at room temperature. ABTS was added to develop the plates, and stop buffer (10\% SDS $\mathrm{w} / \mathrm{v} \mathrm{ddH}_{2} \mathrm{O}$ ) was added to stop the reaction after 5 minutes. OD was measured at $405 \mathrm{~nm}$. For some of the $\mathrm{mAbs}$, individual ELISA curves generated from a series of sixteen 2-fold dilutions of the Ab starting at 10 $\mu \mathrm{g} / \mathrm{mL}$ were applied to a curve-fitting analysis to calculate $\mathrm{Ab}$ affinities $\left(K_{D}\right)$ as described (91).

In vitro neutralization assay. CHO cells were resuspended at $1 \times 10^{5}$ cells $/ \mathrm{mL}$ in $\mathrm{F}-12 \mathrm{~K}$ media (Corning) with L-glutamine and $10 \%$ heat-inactivated FCS, and $100 \mu \mathrm{L}$ of the cell suspension was seeded into each well of the 96 -well plates and cultured overnight $\left(5 \% \mathrm{CO}_{2}, 37^{\circ} \mathrm{C}\right)$. Human $\mathrm{mAbs}$ and plasma samples were diluted to $10 \mu \mathrm{g} / \mathrm{mL}$ and $1 / 100$, respectively, in medium containing TcdB1 or TcdB2 at a final concentration of 0.23 $\mathrm{nM}$ and $0.25 \mathrm{nM}$, respectively, and incubated for 30 minutes at $37^{\circ} \mathrm{C}$. A positive control serum was obtained from rabbits immunized and boosted with $0.1 \mathrm{mg}$ of the CTD fraction of $C$. difficile VPI-10463 ribotype as described previously (57). IgG depletion from plasma samples was achieved using albumin and IgG Depletion SpinTrap columns (GE Life Sciences) prepacked with agarose beads covalently bound to anti-HSA and Protein G. The toxin concentration was calibrated to cause $80 \% \mathrm{CHO}$ cell death. Medium from 24-hour-old cultures was removed and replaced with the Ab/plasma-toxin-medium mixture. Plates were cultured for 24 hours before addition of $100 \mu \mathrm{L} /$ well of media containing 10\% Cell Counting kit-8 (CCK-8) reagent (MilliporeSigma) and an additional 2 hours of incubation. Absorbance at a wavelength of $450 \mathrm{~nm}$ (A450) was then measured, and percent viability was calculated as follows: (A450 of treated [sample-toxin] cells/A450 of untreated [no toxin] cells) $\times 100$.

Dataset availability. Sequences are submitted to the NCBI Sequence Read Archive (SRA), and the project is registered with the BioProject database under SRA accession PRJNA601978 (http://www.ncbi. nlm.nih.gov/bioproject/601978). The accession nos. for the data are: SAMN13878386 (subject 1007), SAMN13878387 (subject 1008), SAMN13878388 (subject 1009) and SAMN13878389 (subject 1013).

Statistics. GraphPad Prism software was used to generate binding curves and calculate equilibrium $K_{D}$ to report $\mathrm{mAb}$ affinity. For multiple comparisons Kruskal-Wallis with Dunn's post hoc test correction was used as indicated. A 2-tailed unpaired $t$ test with Welch's correction was used to compare 2 groups. $P<0.05$ was considered significant.

Study approval. Written informed consent was given by study participants. The human subject studies were approved by the OUHSC IRB (protocol no. 8158) and were performed in accordance with the ethical standards as laid down in the 1964 Declaration of Helsinki and its later amendments.

\section{Author contributions}

HBS designed and performed the experiments, analyzed data, and wrote the manuscript. MLL devised the project, analyzed data, and wrote the manuscript. EJS performed bioinformatics analysis and curated the data. KS generated and quality control-checked the mAbs, analyzed data, and edited the manuscript. JLL provided critical reagents and assisted with neutralization experiments. JDB provided critical reagents, reviewed data, and edited the manuscript. JAJ assisted with subject recruitment, reviewed data, and edited the manuscript.

\section{Acknowledgments}

Brittany Karfonta and Katlyn Beecken at the Oklahoma Shared Clinical and Translational Resources (OSCTR) supported by NIH (NIH award no. U54GM104938) provided assistance with patient recruitment and sample collection. Assistance with data analysis was provided by the Bioinformatics core (supported by NIH award no. P20GM10344). The content is solely the responsibility of the authors and does not necessarily represent the official views of the NIH. The experimental work described in this manuscript was supported by a Team Science research award from the Presbyterian Health Foundation of Oklahoma City. 
We acknowledge the flow cytometry core, Genomics Core, and the Human Ab Core at OMRF for their assistance in cell sorting, sequencing, and $\mathrm{Ab}$ generation, respectively. The authors thank Willard Freeman (OMRF) for access to the Chromium controller and Carol Webb and David Dyer (OUHSC) and Jonathan Wren (OMRF) for helpful discussions.

Address correspondence to: Mark L. Lang, University Of Oklahoma Health Sciences Center, 940 Stanton L. Young Boulevard, Oklahoma City, Oklahoma 73104, USA. Phone: 405.271.2193; Email: Mark-Lang@ouhsc.edu.

EJS's present address is: United States Air Force, Tinker Air Force Base, Oklahoma City, Oklahoma, USA.

1. Lessa FC, Winston LG, McDonald LC, Emerging Infections Program C. difficile Surveillance Team. Burden of Clostridium difficile infection in the United States. N Engl J Med. 2015;372(24):2369-2370.

2. Barbut F, et al. Prospective study of Clostridium difficile infections in Europe with phenotypic and genotypic characterisation of the isolates. Clin Microbiol Infect. 2007;13(11):1048-1057.

3. Bauer MP, et al. Clostridium difficile infection in Europe: a hospital-based survey. Lancet. 2011;377(9759):63-73.

4. Davies KA, et al. Underdiagnosis of Clostridium difficile across Europe: the European, multicentre, prospective, biannual, point-prevalence study of Clostridium difficile infection in hospitalised patients with diarrhoea (EUCLID). Lancet Infect Dis. 2014;14(12):1208-1219.

5. Borren NZ, Ghadermarzi S, Hutfless S, Ananthakrishnan AN. The emergence of Clostridium difficile infection in Asia: A systematic review and meta-analysis of incidence and impact. PLoS One. 2017;12(5):e0176797.

6. George RH, et al. Identification of Clostridium difficile as a cause of pseudomembranous colitis. Br Med J. 1978;1(6114):695.

7. Bartlett JG, Moon N, Chang TW, Taylor N, Onderdonk AB. Role of Clostridium difficile in antibiotic-associated pseudomembranous colitis. Gastroenterology. 1978;75(5):778-782.

8. Larson HE, Price AB, Honour P, Borriello SP. Clostridium difficile and the aetiology of pseudomembranous colitis. Lancet. 1978;1(8073):1063-1066.

9. Rexroth G. [Toxic megacolon in pseudomembranous colitis. Complicated course of antibiotic-induced Clostridium difficile colitis]. Fortschr Med. 1993;111(13):219-223.

10. Dobson G, Hickey C, Trinder J. Clostridium difficile colitis causing toxic megacolon, severe sepsis and multiple organ dysfunction syndrome. Intensive Care Med. 2003;29(6):1030.

11. Elliott B, Chang BJ, Golledge CL, Riley TV. Clostridium difficile-associated diarrhoea. Intern Med J. 2007;37(8):561-568.

12. Karas JA, Enoch DA, Aliyu SH. A review of mortality due to Clostridium difficile infection. J Infect. 2010;61(1):1-8.

13. Sakurai T, Hajiro K, Takakuwa H, Nishi A, Aihara M, Chiba T. Liver abscess caused by Clostridium difficile. Scand J Infect Dis. 2001;33(1):69-70.

14. Tsourous GI, Raftopoulos LG, Kafe EE, Manoleris EK, Makaritsis KP, Pinis SG. A case of pseudomembranous colitis presenting with massive ascites. Eur J Intern Med. 2007;18(4):328-330.

15. Boaz A, Dan M, Charuzi I, Landau O, Aloni Y, Kyzer S. Pseudomembranous colitis: report of a severe case with unusual clinical signs in a young nurse. Dis Colon Rectum. 2000;43(2):264-266.

16. Jacob SS, Sebastian JC, Hiorns D, Jacob S, Mukerjee PK. Clostridium difficile and acute respiratory distress syndrome. Heart Lung. 2004;33(4):265-268.

17. Kuehne SA, Cartman ST, Heap JT, Kelly ML, Cockayne A, Minton NP. The role of toxin A and toxin B in Clostridium difficile infection. Nature. 2010;467(7316):711-713.

18. Lyerly DM, Saum KE, MacDonald DK, Wilkins TD. Effects of Clostridium difficile toxins given intragastrically to animals. Infect Immun. 1985;47(2):349-352.

19. Lyras D, et al. Toxin B is essential for virulence of Clostridium difficile. Nature. 2009;458(7242):1176-1179.

20. Just I, Selzer J, Wilm M, von Eichel-Streiber C, Mann M, Aktories K. Glucosylation of Rho proteins by Clostridium difficile toxin B. Nature. 1995;375(6531):500-503.

21. Just I, et al. The enterotoxin from Clostridium difficile (ToxA) monoglucosylates the Rho proteins. J Biol Chem. 1995;270(23):13932-13936.

22. Yu H, et al. Identification of toxemia in patients with Clostridium difficile infection. PLoS One. 2015;10(4):e0124235.

23. Drudy D, Fanning S, Kyne L. Toxin A-negative, toxin B-positive Clostridium difficile. Int J Infect Dis. 2007;11(1):5-10.

24. Lin Q, et al. Toxin A-Predominant Pathogenic Clostridioides difficile: A Novel Clinical Phenotype. Clin Infect Dis. 2020;70(12):2628-2633

25. Steele J, Feng H, Parry N, Tzipori S. Piglet models of acute or chronic Clostridium difficile illness. J Infect Dis. 2010;201(3):428-434.

26. Steele J, et al. Systemic dissemination of Clostridium difficile toxins A and B is associated with severe, fatal disease in animal models. J Infect Dis. 2012;205(3):384-391.

27. Siarakas S, Damas E, Murrell WG. Is cardiorespiratory failure induced by bacterial toxins the cause of sudden infant death syndrome? Studies with an animal model (the rabbit). Toxicon. 1995;33(5):635-649.

28. Lanis JM, Barua S, Ballard JD. Variations in TcdB activity and the hypervirulence of emerging strains of Clostridium difficile. PLoS Pathog. 2010;6(8):e1001061.

29. Hunt JJ, Ballard JD. Variations in virulence and molecular biology among emerging strains of Clostridium difficile. Microbiol Mol Biol Rev. 2013;77(4):567-581.

30. McDonald LC, et al. An epidemic, toxin gene-variant strain of Clostridium difficile. N Engl J Med. 2005;353(23):2433-2441. 
31. Muto CA, et al. A large outbreak of Clostridium difficile-associated disease with an unexpected proportion of deaths and colectomies at a teaching hospital following increased fluoroquinolone use. Infect Control Hosp Epidemiol. 2005;26(3):273-280.

32. Loo VG, et al. A predominantly clonal multi-institutional outbreak of Clostridium difficile-associated diarrhea with high morbidity and mortality. N Engl J Med. 2005;353(23):2442-2449.

33. Devera TS, et al. Memory B Cells Encode Neutralizing Antibody Specific for Toxin B from the Clostridium difficile Strains VPI 10463 and NAP1/BI/027 but with Superior Neutralization of VPI 10463 Toxin B. Infect Immun. 2016;84(1):194-204.

34. Sheitoyan-Pesant C, Abou Chakra CN, Pépin J, Marcil-Héguy A, Nault V, Valiquette L. Clinical and Healthcare Burden of Multiple Recurrences of Clostridium difficile Infection. Clin Infect Dis. 2016;62(5):574-580.

35. Drekonja DM, Amundson WH, Decarolis DD, Kuskowski MA, Lederle FA, Johnson JR. Antimicrobial use and risk for recurrent Clostridium difficile infection. Am J Med. 2011;124(11):1081.e1-1081.e7.

36. Louie TJ, et al. Effect of age on treatment outcomes in Clostridium difficile infection. J Am Geriatr Soc. 2013;61(2):222-230.

37. Kyne L, Warny M, Qamar A, Kelly CP. Association between antibody response to toxin A and protection against recurrent Clostridium difficile diarrhoea. Lancet. 2001;357(9251):189-193.

38. Marsh JW, Arora R, Schlackman JL, Shutt KA, Curry SR, Harrison LH. Association of relapse of Clostridium difficile disease with BI/NAP1/027. J Clin Microbiol. 2012;50(12):4078-4082.

39. Petrella LA, et al. Decreased cure and increased recurrence rates for Clostridium difficile infection caused by the epidemic C. difficile BI strain. Clin Infect Dis. 2012;55(3):351-357.

40. Gómez S, Chaves F, Orellana MA. Clinical, epidemiological and microbiological characteristics of relapse and re-infection in Clostridium difficile infection. Anaerobe. 2017;48:147-151.

41. Olsen MA, Yan Y, Reske KA, Zilberberg MD, Dubberke ER. Recurrent Clostridium difficile infection is associated with increased mortality. Clin Microbiol Infect. 2015;21(2):164-170.

42. Leav BA, et al. Serum anti-toxin B antibody correlates with protection from recurrent Clostridium difficile infection (CDI). Vaccine. 2010;28(4):965-969.

43. Aronsson B, Granström M, Möllby R, Nord CE. Serum antibody response to Clostridium difficile toxins in patients with Clostridium difficile diarrhoea. Infection. 1985;13(3):97-101

44. Kyne L, Warny M, Qamar A, Kelly CP. Asymptomatic carriage of Clostridium difficile and serum levels of IgG antibody against toxin A. NEngl J Med. 2000;342(6):390-397.

45. Gupta SB, et al. Antibodies to Toxin B Are Protective Against Clostridium difficile Infection Recurrence. Clin Infect Dis. 2016;63(6):730-734.

46. Nakamura $\mathrm{S}$, et al. Isolation of Clostridium difficile from the feces and the antibody in sera of young and elderly adults. Microbiol Immunol. 1981;25(4):345-351.

47. Haines CF, et al. Clostridium difficile in a HIV-infected cohort: incidence, risk factors, and clinical outcomes. AIDS 2013;27(17):2799-2807.

48. Collini PJ, Bauer M, Kuijper E, Dockrell DH. Clostridium difficile infection in HIV-seropositive individuals and transplant recipients. J Infect. 2012;64(2):131-147.

49. Orth $\mathrm{P}$, et al. Mechanism of action and epitopes of Clostridium difficile toxin B-neutralizing antibody bezlotoxumab revealed by X-ray crystallography. J Biol Chem. 2014;289(26):18008-18021.

50. Lowy I, et al. Treatment with monoclonal antibodies against Clostridium difficile toxins. N Engl J Med. 2010;362(3):197-205.

51. Wilcox MH, et al. Bezlotoxumab for Prevention of Recurrent Clostridium difficile Infection. N Engl J Med. 2017;376(4):305-317.

52. Kurosaki T, Kometani K, Ise W. Memory B cells. Nat Rev Immunol. 2015;15(3):149-159.

53. Nutt SL, Hodgkin PD, Tarlinton DM, Corcoran LM. The generation of antibody-secreting plasma cells. Nat Rev Immunol. 2015;15(3):160-171

54. Monaghan TM, Robins A, Knox A, Sewell HF, Mahida YR. Circulating antibody and memory B-Cell responses to C. difficile toxins $\mathrm{A}$ and $\mathrm{B}$ in patients with $\mathrm{C}$. difficile-associated diarrhoea, inflammatory bowel disease and cystic fibrosis. PLoS One. 2013;8(9):e74452.

55. Torres JF, Monath TP. Antigenicity of amino-acid sequences from Clostridium difficile toxin B. J Med Microbiol. 1996;44(6):464-474

56. Babcock GJ, et al. Human monoclonal antibodies directed against toxins A and B prevent Clostridium difficile-induced mortality in hamsters. Infect Immun. 2006;74(11):6339-6347.

57. Lanis JM, Heinlen LD, James JA, Ballard JD. Clostridium difficile 027/BI/NAP1 encodes a hypertoxic and antigenically variable form of TcdB. PLoS Pathog. 2013;9(8):e1003523.

58. Shah HB, et al. Insights From Analysis of Human Antigen-Specific Memory B Cell Repertoires. Front Immunol. $2018 ; 9: 3064$.

59. Barandun S, Morell A, Skvaril F, Oberdorfer A. Deficiency of kappa- or lambda-type immunoglobulins. Blood. 1976;47(1):79-89.

60. Chang B, Casali P. The CDR1 sequences of a major proportion of human germline Ig VH genes are inherently susceptible to amino acid replacement. Immunol Today. 1994;15(8):367-373.

61. Rajewsky K. Clonal selection and learning in the antibody system. Nature. 1996;381(6585):751-758.

62. Sanz I. Multiple mechanisms participate in the generation of diversity of human H chain CDR3 regions. J Immunol. 1991;147(5):1720-1729.

63. Budeus B, Schweigle de Reynoso S, Przekopowitz M, Hoffmann D, Seifert M, Küppers R. Complexity of the human memory B-cell compartment is determined by the versatility of clonal diversification in germinal centers. Proc Natl Acad Sci USA. 2015;112(38):E5281-E5289.

64. Amadou Amani S, Shadid T, Ballard JD, Lang ML. Clostridioides difficile Infection Induces an Inferior IgG Response to That Induced by Immunization and Is Associated with a Lack of T Follicular Helper Cell and Memory B Cell Expansion. Infect Immun. 2020;88(3):e00829-19.

65. Holodick NE, Rodríguez-Zhurbenko N, Hernández AM. Defining Natural Antibodies. Front Immunol. $2017 ; 8: 872$.

66. Weller S, et al. Human blood IgM "memory" B cells are circulating splenic marginal zone B cells harboring a prediversified immunoglobulin repertoire. Blood. 2004;104(12):3647-3654.

67. Keitany GJ, et al. Blood Stage Malaria Disrupts Humoral Immunity to the Pre-erythrocytic Stage Circumsporozoite Protein. Cell Rep. 2016;17(12):3193-3205. 
68. Chua CL, Sam IC, Chiam CW, Chan YF. The neutralizing role of IgM during early Chikungunya virus infection. PLoS One. 2017;12(2):e0171989.

69. Devito C, et al. Human IgM monoclonal antibodies block HIV-transmission to immune cells in cervico-vaginal tissues and across polarized epithelial cells in vitro. Sci Rep. 2018;8(1):10180.

70. Skountzou I, et al. Influenza virus-specific neutralizing IgM antibodies persist for a lifetime. Clin Vaccine Immunol. 2014;21(11):1481-1489.

71. Weitkamp JH, et al. Infant and adult human B cell responses to rotavirus share common immunodominant variable gene repertoires. J Immunol. 2003;171(9):4680-4688.

72. Foreman AL, Van de Water J, Gougeon ML, Gershwin ME. B cells in autoimmune diseases: insights from analyses of immunoglobulin variable (Ig V) gene usage. Autoimmun Rev. 2007;6(6):387-401.

73. Wiesmann UN, DiDonato S, Herschkowitz NN. Effect of chloroquine on cultured fibroblasts: release of lysosomal hydrolases and inhibition of their uptake. Biochem Biophys Res Commun. 1975;66(4):1338-1343.

74. Yamada M, Wasserman R, Reichard BA, Shane S, Caton AJ, Rovera G. Preferential utilization of specific immunoglobulin heavy chain diversity and joining segments in adult human peripheral blood B lymphocytes. J Exp Med. 1991;173(2):395-407.

75. Volpe JM, Kepler TB. Large-scale analysis of human heavy chain V(D)J recombination patterns. Immunome Res. 2008;4:3.

76. Shlomchik MJ, Marshak-Rothstein A, Wolfowicz CB, Rothstein TL, Weigert MG. The role of clonal selection and somatic mutation in autoimmunity. Nature. 1987;328(6133):805-811.

77. Wu YC, Kipling D, Leong HS, Martin V, Ademokun AA, Dunn-Walters DK. High-throughput immunoglobulin repertoire analysis distinguishes between human IgM memory and switched memory B-cell populations. Blood. 2010;116(7):1070-1078.

78. Lee Y, Lim WI, Bloom CI, Moore S, Chung E, Marzella N. Bezlotoxumab (Zinplava) for Clostridium Difficile Infection: The First Monoclonal Antibody Approved to Prevent the Recurrence of a Bacterial Infection. P T. 2017;42(12):735-738

79. Chapin RW, Lee T, McCoy C, Alonso CD, Mahoney MV. Bezlotoxumab: Could This be the Answer for Clostridium difficile Recurrence? Ann Pharmacother. 2017;51(9):804-810.

80. Larabee JL, Krumholz A, Hunt JJ, Lanis JM, Ballard JD. Exposure of neutralizing epitopes in the carboxyl-terminal domain of TcdB is altered by a proximal hypervariable region. J Biol Chem. 2015;290(11):6975-6985.

81. Amanna IJ, Carlson NE, Slifka MK. Duration of humoral immunity to common viral and vaccine antigens. $N E n g l J M e d$. 2007;357(19):1903-1915.

82. Sutton TC, et al. In Vitro Neutralization Is Not Predictive of Prophylactic Efficacy of Broadly Neutralizing Monoclonal Antibodies CR6261 and CR9114 against Lethal H2 Influenza Virus Challenge in Mice. J Virol. 2017;91(24):e01603-17.

83. Bootz A, et al. Protective capacity of neutralizing and non-neutralizing antibodies against glycoprotein B of cytomegalovirus. PLoS Pathog. 2017;13(8):e1006601

84. Lawrence SJ, Dubberke ER, Johnson S, Gerding DN. Clostridium difficile-associated disease treatment response depends on definition of cure. Clin Infect Dis. 2007;45(12):1648; author reply 1649-1648; author reply 1651.

85. Cohen NA, et al. Clostridium difficile fecal toxin level is associated with disease severity and prognosis. United European Gastroenterol J. 2018;6(5):773-780.

86. Henderson M, Bragg A, Fahim G, Shah M, Hermes-DeSantis ER. A Review of the Safety and Efficacy of Vaccines as Prophylaxis for Clostridium difficile Infections. Vaccines (Basel). 2017;5(3):E25.

87. Krivan HC, Wilkins TD. Purification of Clostridium difficile toxin A by affinity chromatography on immobilized thyroglobulin Infect Immun. 1987;55(8):1873-1877.

88. Zheng GX, et al. Massively parallel digital transcriptional profiling of single cells. Nat Commun. 2017;8:14049.

89. Gupta NT, Vander Heiden JA, Uduman M, Gadala-Maria D, Yaari G, Kleinstein SH. Change-O: a toolkit for analyzing largescale B cell immunoglobulin repertoire sequencing data. Bioinformatics. 2015;31(20):3356-3358.

90. Smith K, et al. Rapid generation of fully human monoclonal antibodies specific to a vaccinating antigen. Nat Protoc. 2009;4(3):372-384.

91. Smith K, et al. Fully human monoclonal antibodies from antibody secreting cells after vaccination with Pneumovax 23 are serotype specific and facilitate opsonophagocytosis. Immunobiology. 2013;218(5):745-754. 